\title{
Variability in State-Dependent Plasticity of Intrinsic Properties during Cell-Autonomous Self- Regulation of Calcium Homeostasis in Hippocampal Model Neurons ${ }^{1,2,3}$
}

\author{
Sunandha Srikanth, ${ }^{1,2}$ and ${ }^{\mathbb{D}}$ Rishikesh Narayanan ${ }^{1}$
}

DOI:http://dx.doi.org/10.1523/ENEURO.0053-15.2015

${ }^{1}$ Cellular Neurophysiology Laboratory, Molecular Biophysics Unit, Indian Institute of Science, Bangalore 560012 , India, and ${ }^{2}$ Undergraduate program, Indian Institute of Science, Bangalore 560 012, India

\begin{abstract}
How do neurons reconcile the maintenance of calcium homeostasis with perpetual switches in patterns of afferent activity? Here, we assessed state-dependent evolution of calcium homeostasis in a population of hippocampal pyramidal neuron models, through an adaptation of a recent study on stomatogastric ganglion neurons. Calcium homeostasis was set to emerge through cell-autonomous updates to 12 ionic conductances, responding to different types of synaptically driven afferent activity. We first assessed the impact of theta-frequency inputs on the evolution of ionic conductances toward maintenance of calcium homeostasis. Although calcium homeostasis emerged efficaciously across all models in the population, disparate changes in ionic conductances that mediated this emergence resulted in variable plasticity to several intrinsic properties, also manifesting as significant differences in firing responses across models. Assessing the sensitivity of this form of plasticity, we noted that intrinsic neuronal properties and the firing response were sensitive to the target calcium concentration and to the strength and frequency of afferent activity. Next, we studied the evolution of calcium homeostasis when afferent activity was switched, in different temporal sequences, between two behaviorally distinct types of activity: theta-frequency inputs and sharp-wave ripples riding on largely silent periods. We found that the conductance values, intrinsic properties, and firing response of neurons exhibited differential robustness to an intervening switch in the type of afferent activity. These results unveil critical dissociations between different forms of homeostasis, and call for a systematic evaluation of the impact of state-dependent switches in afferent activity on neuronal intrinsic properties during neural coding and homeostasis.
\end{abstract}

Key words: hippocampus; homeostasis; intrinsic plasticity; ion channels; sharp wave ripples; theta frequency oscillations

\section{Significance Statement}

A growing body of theoretical and experimental evidence points to neuronal maintenance of calcium homeostasis. The maintenance of such constancy in the face of perpetual switches in behaviorally driven afferent activity is a paradox, and has not been quantitatively assessed. We assessed cell-autonomous calcium homeostasis in a population of hippocampal model neurons subjected to switches in afferent activity. We found that neuronal conductances and intrinsic properties could undergo variable and significant plasticity toward maintenance of calcium homeostasis through a regime of such behavioral statedependent changes. Our results also reveal that the maintenance of calcium homeostasis does not necessarily translate to the emergence of individual channelostasis or of functional homeostasis (including firing rate), thereby establishing critical dissociations between different forms of homeostasis. 


\section{Introduction}

Afferent activity patterns to hippocampal pyramidal neurons manifest well established distinctions that reflect the behavioral state of the animal (Anderson et al., 2007). Whereas rapid eye movement (REM) sleep and exploratory activity are associated with theta-dominant oscillatory (4-10 $\mathrm{Hz}$ ) inputs, non-REM sleep and nonexploratory activity correspond to sharp-wave ripples (SWRs; ripple frequency, $100-200 \mathrm{~Hz}$ ) riding on largely silent (inter-SWR frequency, 1-3 Hz) periods (Buzsáki, 1986, 198920022006; Buzsáki et al., 1992; Wilson and McNaughton, 1994; Ylinen et al., 1995; Csicsvari et al., 1999; Louie and Wilson, 2001; Tononi and Cirelli, 2006; Montgomery et al., 2008; Mizuseki et al., 2011; Grosmark et al., 2012; English et al., 2014). Additionally, a growing body of theoretical and experimental evidence points to neuronal maintenance of calcium/activity homeostasis, through changes in synaptic and/or intrinsic properties (LeMasson et al., 1993; Siegel et al., 1994; Turrigiano, 1999; Turrigiano and Nelson, 2000, 2004; Prinz et al., 2004; Triesch, 2007; Turrigiano, 2007; Marder, 2011; Honnuraiah and Narayanan, 2013; Marder et al., 2014; O'Leary et al., 2014). How do neurons reconcile the maintenance of calcium homeostasis with perpetual state-dependent switches in afferent activity patterns? Existing literature has explored switches in afferent activity from the perspective of firing rate modulation, synaptic normalization and plasticity, especially during sleep-(Tononi and Cirelli, 2006; Chauvette et al., 2012; Grosmark et al., 2012; Barnes and Wilson, 2014) - and from the perspective of how dendritic nonlinearities endow hippocampal neurons with the ability to adapt to changes in afferent activity (Gasparini and Magee, 2006). However, the question of how neurons implementing calcium homeostasis through changes in ionic conductances react to state-dependent switches in afferent activity has not been addressed. Specifically, under a selfregulating, cell-autonomous schema for calcium homeostasis, are there changes in neuronal firing, conductance values, and intrinsic properties that are consequent to switches in afferent activity?

To address this, we first arrived at a population of 78 experimentally constrained (with 7 different physiological measurements) CA1 pyramidal neuron models involving 12 ion channels, derived from a randomized population of 4000 models built from uniform sampling of 48 different

Received May 18, 2015; accepted August 3, 2015; First published August 11, 2015.

${ }^{1}$ The authors report no conflict of interest.

${ }^{2}$ Author contributions: S.S. and R.N. designed research; S.S. performed research; S.S. analyzed data; S.S. and R.N. wrote the paper.

${ }^{3}$ This work was supported by the Department of Science and Technology (R.N.), the Indian Institute of Science (R.N.), and a fellowship from the Kishore Vaigyanik Protsahan Yojana (S.S.). We thank members of the cellular neurophysiology laboratory for helpful comments on a draft version of the paper.

Correspondence should be addressed to Dr Rishikesh Narayanan, Molecular Biophysics Unit, Indian Institute of Science, Bangalore 560 012, India. E-mail: rishi@mbu.iisc.ernet.in.

DOI:http://dx.doi.org/10.1523/ENEURO.0053-15.2015

Copyright @ 2015 Srikanth and Narayanan

This is an open-access article distributed under the terms of the Creative Commons Attribution 4.0 International, which permits unrestricted use, distribution and reproduction in any medium provided that the original work is properly attributed. model parameters. Next, we adapted a recent study on cell-autonomous self-evolution of calcium homeostasis in neurons of the crab stomatogastric ganglion (O'Leary et al., 2014) to hippocampal neurons. We ensured that the adapted model included ion channels derived from hippocampal pyramidal neurons, was endowed with detailed calcium-handling mechanisms (including pumps, buffers and the endoplasmic reticulum; Ashhad and Narayanan, 2013) and received different types of afferent activity through AMPA and NMDA receptors. The temporal evolution of messenger RNAs (mRNAs) and conductances corresponding to each of the 12 channels was independently monitored in each of the 78 valid models, with the time courses of mRNA evolution controlled by ionic conductances obtained from the corresponding valid model. Within this modeling framework for cell-autonomous evolution of calcium homeostasis, we tested the impact of switches in afferent activity (between theta oscillations and SWR inputs) on neuronal conductances and intrinsic properties.

Our results suggest that neuronal ion-channel conductances and intrinsic properties could undergo significant plasticity in the process of maintaining calcium homeostasis through a regime of behavioral state-dependent changes in afferent activity. The sign and strength of such intrinsic plasticity were dependent on the specific activity pattern, the temporal sequence of switches, and the specific neuronal model. These results call for a significant reassessment of the impact of state-dependent switches in afferent activity on neuronal and network physiology, especially accounting for potentially adaptive changes in intrinsic properties.

\section{Materials and Methods}

\section{Neuronal model and ion channels}

To study state-dependent and cell-autonomous calcium homeostasis in hippocampal CA1 pyramidal neurons, we used a single compartmental cylindrical model of diameter $(d)=100 \mu \mathrm{m}$ and length $(L)=100 \mu \mathrm{m}$. Passive properties were set as specific membrane resistance $\left(R_{\mathrm{m}}\right)=35 \mathrm{k} \Omega . \mathrm{cm}^{2}$ and specific membrane capacitance $\left(C_{\mathrm{m}}\right)=1 \mu \mathrm{F} / \mathrm{cm}^{2}$. These settings ensured that the passive input resistance $\left(R_{\text {in }}\right)$ was $\sim 111 \mathrm{M} \Omega$ and the passive membrane time constant was $35 \mathrm{~ms}$ (Narayanan and Johnston, 2007, 2008). The neuronal compartment consisted of 11 conductance-based models for ion channels (Fig. 1A) namely, fast sodium (NaF), delayed-rectifier potassium (KDR), $A$-type potassium (KA), M-type potassium (KM), $T$-type calcium (CaT), $R$-type calcium (CaR), $N$-type calcium (CaN), L-type calcium (CaL), hyperpolarizationactivated cyclic nucleotide gated channel ( $\mathrm{HCN}$ or $h$ ), small conductance (SK) and big conductance calciumactivated potassium (BK) channels. The channel kinetics for $\mathrm{NaF}, \mathrm{KDR}$, and KA were obtained from Hoffman et al. (1997) and Migliore et al. (1999), for CaT from Shah et al. (2011), for KM from Migliore et al. (2006), for CaR and CaL from Magee and Johnston (1995) and Poirazi et al. (2003), CaN and SK from Migliore et al. (1995), for HCN from Magee (1998) and Poolos et al. (2002), and for BK from Moczydlowski and Latorre (1983). The reversal potentials 
A

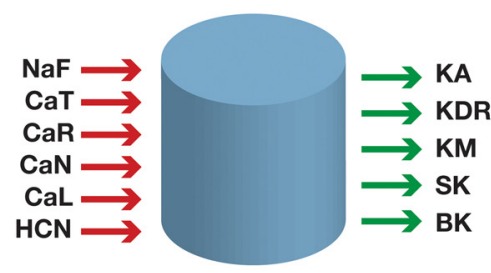

C

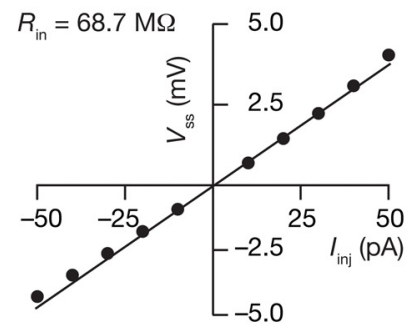

E

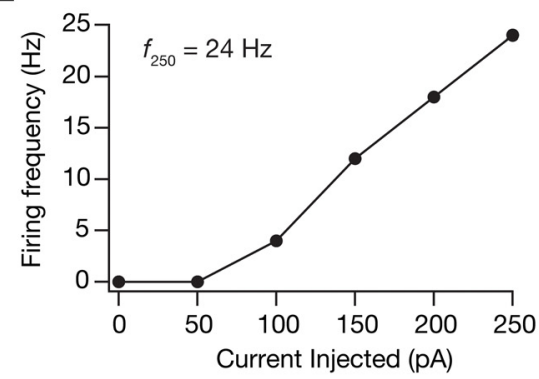

G

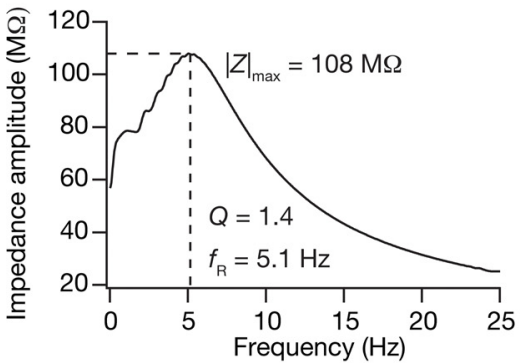

B

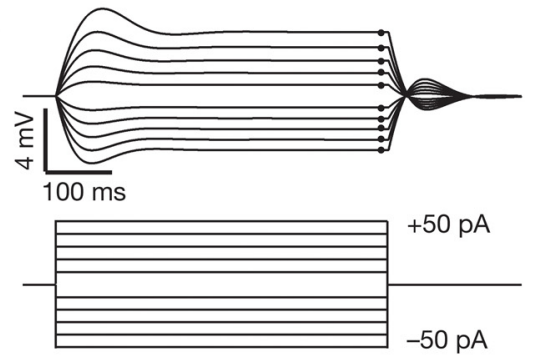

D

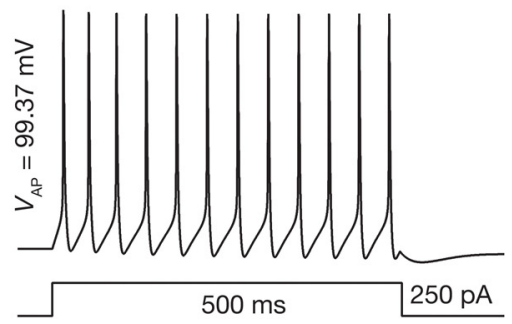

F
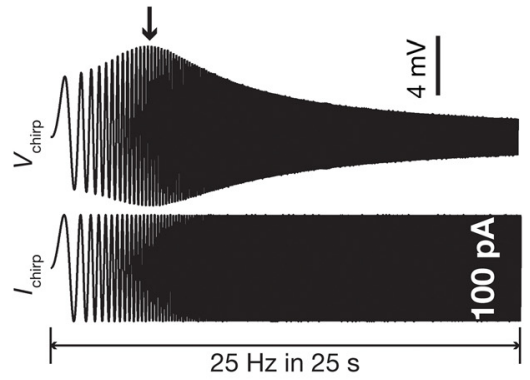

H

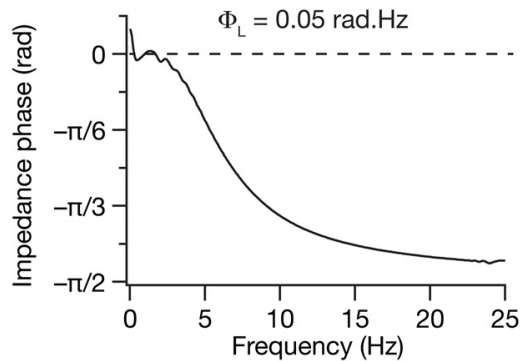

Figure 1. Measurements of intrinsic response dynamics in the base neuronal model. $\boldsymbol{A}$, The cylindrical model used in this study showing the 11 ion channels inserted. The red arrows denote inward currents and the green arrows denote outward currents. $\boldsymbol{B}$, Voltage responses (top) of the base neuronal model to current pulses (bottom) ranging from -50 to $50 \mathrm{pA}$ in steps of $10 \mathrm{pA}$. C, The steady state voltages from $(\boldsymbol{B})$ are plotted against the corresponding current injected. The slope of the resulting $V-I$ plot was defined as the input resistance, $R_{\mathrm{in}}$. $\boldsymbol{D}$, The voltage response of the base neuronal model to a current injection of $250 \mathrm{pA}$. The amplitude of the last action potential was defined as the action potential (AP) amplitude, $V_{\mathrm{AP}}$. $E$, The AP firing frequency $(f)$ versus injected current plot showing the frequency of firing with current injections from 0 to $250 \mathrm{pA}$ in steps of $50 \mathrm{pA}$. The number of APs elicited by the model in response to a $250 \mathrm{pA}, 500 \mathrm{~ms}$ current pulse was used to compute the firing rate at $250 \mathrm{pA}, f_{250}$. $\boldsymbol{F}$. The model's voltage response (top) to a chirp current stimulus of peak-to-peak amplitude of $100 \mathrm{pA}$, with frequency linearly increasing from 0 to $25 \mathrm{~Hz}$ in $25 \mathrm{~s}$ (bottom). $\boldsymbol{G}$, The impedance amplitude profile $|Z(f)|$ derived from traces in $\boldsymbol{F}$. The frequency at which the impedance amplitude is maximum $\left(|Z|_{\max }\right)$ was defined as the resonance frequency, $f_{\mathrm{R}}$. The strength of resonance, $Q$, was taken as the ratio of $\left|Z\left(f_{\mathrm{R}}\right)\right|$ to $|Z(0.5)|$. $\boldsymbol{H}$, The impedance phase profile $(\phi(f))$ with the area under the inductive part of the curve defined as the total inductive phase $\left(\Phi_{\lrcorner}\right)$.

for $\mathrm{K}^{+}$and $\mathrm{Na}^{+}$ions were set as -90 and $+55 \mathrm{mV}$, respectively, and for the $\mathrm{HCN}$ channel as $-30 \mathrm{mV}$. Accounting for the leak conductance $\left(g_{\text {leak }}=1 / R_{\mathrm{m}}\right)$, this configuration meant the presence of 12 ion channels in our model.

\section{Synaptic receptors}

Excitatory synapses containing AMPA and NMDA receptors, modeled using the Goldman-Hodgkin-Katz formulation (Goldman, 1943; Hodgkin and Katz, 1949; Ashhad and Narayanan, 2013) were introduced in the model. Spe- 
cifically, a canonical synapse consisting of colocalized NMDA receptor (NMDAR) and AMPA receptor (AMPAR) was modeled as in Narayanan and Johnston (2010). The NMDAR current was modeled as a combination of three different types of ionic currents namely $\mathrm{Ca}^{2+}, \mathrm{Na}^{+}$and $\mathrm{K}^{+}$:

$$
I_{\text {NMDAR }}(v, t)=I_{\text {NMDAR }}^{\text {Na }}(v, t)+I_{N M D A R}^{K}(v, t)+I_{\text {NMDAR }}^{\text {Ca }}(v, t),
$$

where,

$$
\begin{gathered}
I_{N M D A R}^{N a}(v, t)=P_{\text {NMDAR }} P_{N a} M g B(v) \frac{v F^{2}}{R T} \\
\left(\frac{[N a]_{i}-[N a]_{0} \exp \left(-\frac{v F}{R T}\right)}{1-\exp \left(-\frac{v F}{R T}\right)}\right), \\
I_{N M D A R}^{K}(v, t)=P_{\text {NMDAR }} P_{K} M g B(v) \frac{v F^{2}}{R T} \\
\left(\frac{[K]_{i}-[K]_{0} \exp \left(-\frac{v F}{R T}\right)}{1-\exp \left(-\frac{v F}{R T}\right)}\right), \\
I_{N M D A R}^{a}(v, t)=P_{\text {NMDAR }} P_{C a} M g B(v) \frac{4 v F^{2}}{R T} \\
\left(\frac{[C a]_{i}-[C a]_{0} \exp \left(-\frac{2 v F}{R T}\right)}{1-\exp \left(-\frac{2 v F}{R T}\right)}\right),
\end{gathered}
$$

where $P_{\text {NMDAR }}$ defined the maximum permeability of the NMDAR; $P_{\mathrm{Ca}}=10.6, P_{\mathrm{Na}}=1, P_{K}=1$ (Mayer and Westbrook, 1987; Canavier, 1999). Extracellular and intracellular concentrations of ions were as follows (in $\mathrm{mm}$ ): $[\mathrm{Na}]_{i}=18,[\mathrm{Na}]_{o}=140,[K]_{i}=140,[K]_{o}=5,[\mathrm{Ca}]_{i}=50 \times 10^{-6}$, $[\mathrm{Ca}]_{O}=2$. These ionic concentrations set the $\mathrm{Na}^{+}$equilibrium potential at $+55 \mathrm{mV}$ and $\mathrm{K}^{+}$equilibrium potential at $-90 \mathrm{mV} . \mathrm{MgB}(\mathrm{v})$ governed the $\mathrm{Mg}^{2+}$ dependence of the NMDAR current (Jahr and Stevens, 1990):

$$
\operatorname{MgB}(v)=\left(1+\frac{[M g]_{0} \exp (-0.062 v)}{3.57}\right)^{-1},
$$

with the default value of $[\mathrm{Mg}]_{\text {o }}$ set at $2 \mathrm{~mm}$.

Current through the AMPAR was modeled as the sum of currents carried by sodium and potassium ions:

$$
I_{\text {AMPAR }}(v, t)=I_{A M P A R}^{N a}(v, t)+I_{A M P A R}^{K}(v, t),
$$

where,

$$
I_{A M P A R}^{N a a}(v, t)=P_{\text {AMPAR }} P_{N a} \frac{V F^{2}}{R T}\left(\frac{[N a]_{i}-[N a]_{o} \exp \left(-\frac{v F}{R T}\right)}{1-\exp \left(-\frac{v F}{R T}\right)}\right),
$$

$$
I_{\text {AMPAR }}^{K}(v, t)=P_{\text {AMPAR }} P_{K} \frac{v F^{2}}{R T}\left(\frac{[K]_{i}-[K]_{0} \exp \left(-\frac{v F}{R T}\right)}{1-\exp \left(-\frac{v F}{R T}\right)}\right) \text {,(8) }
$$

where $P_{\text {AMPAR }}$ defined the maximum permeability of the AMPAR. $P_{\mathrm{Na}}$ was taken to be equal to $P_{K}$ (Dingledine et al., 1999). The relationship between AMPAR and NMDAR permeabilities was defined as follows:

$$
P_{\text {NMDAR }}=N A R \times P_{\text {AMPAR }},
$$

where NAR represented the NMDAR-AMPAR ratio, with its default value set at 1.5.

\section{Calcium dynamics}

Calcium handling mechanisms to take care of the calcium reactions, radial diffusion, and buffers were adopted from Ashhad and Narayanan (2013). The following partial differential equation to govern the cytosolic calcium dynamics was used (Sneyd et al., 1995; Fink et al., 2000):

$$
\begin{aligned}
\frac{d\left[\mathrm{Ca}^{2+}\right]}{d t}= & D_{c a} \nabla^{2}\left[\mathrm{Ca}^{2+}\right]+\beta\left(J_{\text {leak }}-J_{\text {SERCA }}\right) \\
& +R_{\text {buf }}+J_{\text {VGCC }}-J_{\text {pump }},
\end{aligned}
$$

where $D_{\mathrm{Ca}}$ is the diffusion constant for $\left[\mathrm{Ca}^{2+}\right]$ experimentally determined from Allbritton et al. (1992) and Klingauf and Neher (1997); $\beta$ is the density of leak channels and SERCA pumps on the endoplasmic reticulum (ER) membrane; $J_{\text {VGCC }}, J_{\text {SERCA }}, R_{\text {buf }}, J_{\text {pump }}$, and $J_{\text {leak }}$ are the calcium flux due to voltage-gated calcium channels (VGCCs), sarcoendoplasmic reticulum calcium ATPase (SERCA) pumps, static buffers, membrane pumps, and leak channels respectively. Radial diffusion of calcium was taken care of by compartmentalizing the cylinder into four concentric annuli. The calcium concentration on the outermost annulus was considered as the cytosolic calcium, $\left[\mathrm{Ca}^{2+}\right]_{\mathrm{c}}$ (Carnevale and Hines, 2006; Ashhad and Narayanan, 2013). The calcium influx into the cytosol through the ER leak channels was modeled as follows (Fink et al., 2000; Ashhad and Narayanan, 2013):

$$
J_{\text {leak }}=L\left(1-\frac{\left[\mathrm{Ca}^{2+}\right]}{\left[\mathrm{Ca}^{2+}\right]_{E R}}\right) \mathrm{mM} / \mathrm{ms},
$$

where the leak constant $L$ was chosen such that at resting state $(-65 \mathrm{mV})$, there was no net flux of calcium through the leak channels on the ER membrane. The influx of calcium through the VGCCs and NMDARs in our study $(L-, T-, R-$, and $N$-type calcium channels) was modeled as follows (Poirazi et al., 2003; Ashhad and Narayanan, 2013):

$$
J_{V G C C}=-\frac{I_{C a} \times \pi \times \text { diam }}{2 \times F} \mathrm{mM} / \mathrm{ms},
$$

where $I_{\mathrm{Ca}}$ represented the calcium current through the VGCCs/NMDARs, diam is the diameter of the compartment, and $F$ is the Faraday constant. The negative sign indicates the inward nature of $I_{\mathrm{Ca}}$, and accounts for the 
positive flux of calcium ions with increase in $I_{\mathrm{Ca}}$. The uptake of calcium by the SERCA pump was modeled as follows (Fink et al., 2000; Ashhad and Narayanan, 2013):

$$
J_{\text {SERCA }}=V_{\max } \frac{\left[\mathrm{Ca}^{2+}\right]^{2}}{\left[\mathrm{Ca}^{2+}\right]^{2}+K_{p}^{2}} \mathrm{mM} / \mathrm{ms},
$$

where $V_{\max }$ is the average amplitude of uptake by the pump $\left(1 \times 10^{-4} \mathrm{~mm} / \mathrm{ms}\right)$ and $K_{\mathrm{p}}$ is the dissociation constant of calcium binding to the pump $(0.27 \mu \mathrm{M})$. $\mathrm{Ca}^{2+}$ extrusion through plasma membrane pumps was regulated by a threshold on the cytosolic calcium $\left(\left[\mathrm{Ca}^{2+}\right]_{c}\right)$. The pumps were inactive below a critical $\mathrm{Ca}^{2+}$ concentration, $\left[\mathrm{Ca}^{2+}\right]_{\mathrm{crt}}$, above which the extrusion rate depended linearly on $\left[\mathrm{Ca}^{2+}\right]_{\mathrm{c}}$ (Fink et al., 2000):

$$
J_{\text {pump }}=\left\{\begin{array}{ccc}
\gamma\left(\left[\mathrm{Ca}^{2+}\right]_{c}-\left[\mathrm{Ca}^{2+}\right]_{c r t}\right) & : & {\left[\mathrm{Ca}^{2+}\right]_{c} \geq\left[\mathrm{Ca}^{2+}\right]_{c r t}} \\
0 & : & \text { otherwise }
\end{array},\right.
$$

where $\left[\mathrm{Ca}^{2+}\right]_{c r t}$ was set at $0.2 \mu \mathrm{M}$, and $\gamma(8 \mu \mathrm{m} / \mathrm{s})$ defines the sensitivity of pump extrusion (Herrington et al., 1996; Fink et al., 2000; Ashhad and Narayanan, 2013). The rate of change in calcium due to the stationary buffers was modeled as follows (Ashhad and Narayanan, 2013):

$$
\begin{gathered}
R_{\text {buf }}=-k_{\text {on }}\left[\mathrm{Ca}^{2+}\right]\left[B_{\text {buf }}\right]+k_{\text {off }}\left[\mathrm{Ca}^{2+} B_{\text {buf }}\right], \\
\frac{d\left[B_{\text {buf }}\right]}{d t}=\frac{d\left[\mathrm{Ca}^{2+} B_{\text {buf }}\right]}{d t}=R_{\text {buf }}, \\
K_{\text {buf }}=\frac{k_{\text {off }}}{k_{\text {on }}},
\end{gathered}
$$

where $\left[B_{\text {buf }}\right](=450 \mu \mathrm{M})$ and $\left[\mathrm{Ca}^{2+} B_{\text {buf }}\right]$ represented the concentrations of free buffer and calcium bound buffer in the cell. $k_{\text {on }}$ and $k_{\text {off }}$ denoted the on and off rate constants for calcium binding to the buffer. Note that Eq. (16) constitutes a pseudo steady-state approximation, considering free buffer and calcium bound buffer to be in equilibrium. The value of $K_{\text {buf }}$ was set at $10 \mu \mathrm{M}$ (Klingauf and Neher, 1997; Fink et al., 2000; Ashhad and Narayanan, 2013).

\section{Measurements}

The excitability of the neuronal model was characterized by measuring its firing rate at $250 \mathrm{pA}\left(f_{250} ; \mathrm{Hz}\right)$, action potential amplitude $\left(V_{\mathrm{AP}} ; \mathrm{mV}\right)$, input resistance $\left(R_{\text {in }} ; \mathrm{M} \Omega\right)$ and maximum impedance amplitude $\left(|Z|_{\max } ; M \Omega\right)$. The intrinsic response dynamics of the neuron were characterized by measuring the resonance frequency $\left(f_{\mathrm{R}} ; \mathrm{Hz}\right)$, strength of resonance $(Q)$ and total inductive phase $\left(\Phi_{\mathrm{L}}\right.$; rad. $\mathrm{Hz}$ ). These standard measurements (Fig. 1) have been previously used to characterize CA1 pyramidal neurons. Firing rate at $250 \mathrm{pA}$ was taken as twice the number of action potentials fired when a current of $250 \mathrm{pA}$ was injected into the neuron for $500 \mathrm{~ms}$ (Fig. 1D,E). Action potential amplitude was calculated as the difference between the peak voltage of the action potential and the resting membrane voltage $(-65 \mathrm{mV})$. Input resistance was measured by injecting currents of $-50 \mathrm{pA}$ to $50 \mathrm{pA}$, in steps of $10 \mathrm{pA}$, for $500 \mathrm{~ms}$ (Fig. 1B), recording the corresponding steady-state voltage deflection from $-65 \mathrm{mV}$ and taking the slope of the linear fit to the resulting $V-I$ plot (Fig. 1C). To quantify the intrinsic response dynamics of the neuron, we injected a current in the form of a sinusoidal chirp stimulus of constant amplitude (50 pA) and a linearly increasing frequency $(0-25 \mathrm{~Hz}$ in $25 \mathrm{~s}$; Fig. $1 F)$. The impedance as a function of frequency $(Z(f))$ was obtained by dividing the Fourier transform of the voltage response by the Fourier transform of the injected chirp current. The impedance amplitude profile (Fig. 1G) was calculated as the magnitude of this impedance $Z(f)$ which is given as follows:

$$
|Z(f)|=\sqrt{(\operatorname{Re}(Z(f)))^{2}+(\operatorname{Im}(Z(f)))^{2}},
$$

where $\operatorname{Re}(Z(f))$ and $\operatorname{Im}(Z(f))$ are the real and imaginary parts of the complex valued function $Z(f)$. The frequency at which $|Z(f)|$ is maximum is called the resonance frequency, $f_{\mathrm{R}}$. The impedance amplitude at the resonance frequency, $\left|Z\left(f_{\mathrm{R}}\right)\right|$, denotes the maximum impedance amplitude, $|Z|_{\text {max }}$. The strength of resonance, $Q$, was computed as the ratio of the maximum impedance amplitude profile and the impedance amplitude at $0.5 \mathrm{~Hz}$. The impedance phase profile $(\phi(f)$; Fig. $1 H)$ was calculated as follows:

$$
\phi(f)=\tan ^{-1} \frac{\operatorname{Im}(Z(f))}{\operatorname{Re}(Z(f))} .
$$

Total inductive phase was defined as the area under the inductive part of curve $\phi(f)$ (Narayanan and Johnston, 2008) which is given by the following:

$$
\Phi_{L}(f)=\int_{\phi(f)>0} \phi(f) d f .
$$

\section{Global sensitivity analysis}

We used the global sensitivity analysis (GSA), a random sampling technique similar to previously used approaches (Bhalla and Bower, 1993; Foster et al., 1993; Goldman et al., 2001; Golowasch et al., 2002; Prinz et al., 2003, 2004; Achard and De Schutter, 2006; Tobin et al., 2006; Reid et al., 2007; Hobbs and Hooper, 2008; Weaver and Wearne, 2008; Taylor et al., 2009; Rathour and Narayanan, 2012b, 2014) to study the effect of the variability in and interactions among the passive and active properties of the neuron on activity-dependent calcium homeostasis. Four thousand models were generated by choosing a unique value for each of the 48 parameters (spanning passive and active properties) from uniform distributions around appropriate base values (Table 1). The base values of parameters were obtained by hand-tuning a base model. As all the 4000 models could not be expected to have biologically realistic measurements, we validated the models by constraining the seven measurements to have values within experimentally determined ranges for CA1 pyramidal neurons (Table 2). Doing so, we found 78 of $4000(\sim 2 \%)$ neuronal models to be physiologically realistic, and called these as valid models. All further analyses were performed on these 78 valid neuronal models. 
Table 1. Parameters, their default values in the base model and the range over which random sampling was performed during global sensitivity analysis

\begin{tabular}{|c|c|c|c|c|}
\hline & Parameter, unit & Symbol & Default value & Testing range \\
\hline \multicolumn{5}{|c|}{ Passive parameters } \\
\hline 2 & Specific membrane conductance, $\mu \mathrm{F} / \mathrm{cm}^{2}$ & $C_{\mathrm{m}}$ & 1 & 0.5 to 1.5 \\
\hline \multicolumn{5}{|c|}{ Na channel parameters } \\
\hline 3 & Maximal conductance, $\mathrm{S} / \mathrm{cm}^{2}$ & $N a-g$ & 0.007 & 0.005 to 0.01 \\
\hline 4 & Inactivation time constant, ms & $\mathrm{Na}-\tau_{\mathrm{h}}$ & 2.34 & 1.87 to 2.81 \\
\hline 5 & Activation time constant, ms & $\mathrm{Na}-\tau_{\mathrm{m}}$ & 0.163 & 0.13 to 0.20 \\
\hline 8 & $V_{1 / 2}$ activation, $\mathrm{mV}$ & $N a-V_{m}$ & -30 & -32 to -28 \\
\hline 9 & $V_{1 / 2}$ slow inactivation, $\mathrm{mV}$ & $\mathrm{Na}-V_{\mathrm{s}}$ & -60 & -62 to -58 \\
\hline \multicolumn{5}{|c|}{ KDR channel parameters } \\
\hline 10 & Maximal conductance, $\mathrm{S} / \mathrm{cm}^{2}$ & $D R-g$ & 0.003 & 0.001 to 0.005 \\
\hline 11 & Activation time constant, ms & $D R-\tau_{\mathrm{n}}$ & 222.9 & 111.45 to 445.8 \\
\hline 12 & $V_{1 / 2}$ activation, $\mathrm{mV}$ & $D R-V_{\mathrm{n}}$ & 13 & 10 to 15 \\
\hline 16 & $V_{1 / 2}$ inactivation, $\mathrm{mV}$ & $A-V_{1}$ & -56 & -60 to -50 \\
\hline 17 & $V_{1 / 2}$ activation, $\mathrm{mV}$ & $A-V_{\mathrm{n}}$ & 11 & 8 to 15 \\
\hline \multicolumn{5}{|c|}{ CaT channel parameters } \\
\hline 18 & Maximal conductance, $\mathrm{mS} / \mathrm{cm}^{2}$ & $T-g$ & 0.1 & 0.05 to 0.2 \\
\hline 19 & Inactivation time constant, ms & $T-\tau_{\mathrm{h}}$ & 31.02 & 10.24 to 46.53 \\
\hline 20 & Activation time constant, ms & $T-\tau_{\mathrm{m}}$ & 0.858 & 0.43 to 1.72 \\
\hline 21 & $V_{1 / 2}$ inactivation, $\mathrm{mV}$ & $T-V_{\mathrm{h}}$ & -75 & -80 to -70 \\
\hline 22 & $V_{1 / 2}$ activation, $\mathrm{mV}$ & $T-V_{\mathrm{m}}$ & -28 & -25 to -15 \\
\hline \multicolumn{5}{|c|}{ HCN channel parameters } \\
\hline 23 & Maximal conductance, $\mathrm{mS} / \mathrm{cm}^{2}$ & $h-g$ & 0.08 & 0.005 to 0.05 \\
\hline 24 & Activation time constant, ms & $h-\tau_{1}$ & 28.5 & 20.52 to 71.25 \\
\hline 25 & $V_{1 / 2}$ activation, $\mathrm{mV}$ & $h-V_{1}$ & -81 & -85 to -70 \\
\hline \multicolumn{5}{|c|}{ CaL channel parameters } \\
\hline 33 & $V_{1 / 2}$ activation, $\mathrm{mV}$ & $R-V_{\mathrm{m}}$ & 3 & -2 to 7 \\
\hline \multicolumn{5}{|c|}{ SK channel parameters } \\
\hline 34 & $C a_{1 / 2}$ activation, $\mathrm{nm}$ & SK-Ca & 140 & 110 to 180 \\
\hline 35 & Maximal conductance, $\mu \mathrm{S} / \mathrm{cm}^{2}$ & $S K-g$ & 1 & 0.5 to 5 \\
\hline 36 & Activation time constant, ms & $S K-\tau$ & 196.8 & 98.4 to 393.6 \\
\hline \multicolumn{5}{|c|}{ BK channel parameters } \\
\hline 37 & Maximal conductance, $\mu \mathrm{S} / \mathrm{cm}^{2}$ & $B K-g$ & 1 & 0.5 to 5 \\
\hline 38 & Slope of Ca activation (mM) & $B K-k_{1}$ & $4.8 \times 10^{-4}$ & $2.8 \times 10^{-4}$ to $6.8 \times 10^{-4}$ \\
\hline 39 & $C a_{1 / 2}$ activation (nM) & $B K-k_{2}$ & 0.13 & 0.08 to 0.18 \\
\hline 40 & Activation time constant, ms & $B K-\tau$ & 8.04 & 4.04 to 16.08 \\
\hline \multicolumn{5}{|c|}{ KM channel parameters } \\
\hline 41 & Maximal conductance, $\mu \mathrm{S} / \mathrm{cm}^{2}$ & $M-g$ & 1 & 0.5 to 5 \\
\hline 42 & Activation time constant, ms & $M-\tau$ & 6662 & 3331 to 13323 \\
\hline 43 & $V_{1 / 2}$ activation, $\mathrm{mV}$ & $M-V$ & -40 & -45 to -35 \\
\hline \multicolumn{5}{|c|}{ CaN channel parameters } \\
\hline 44 & Maximal conductance, $\mu \mathrm{S} / \mathrm{cm}^{2}$ & $N-g$ & 100 & 50 to 200 \\
\hline 45 & Inactivation time constant, ms & $N-\tau_{\mathrm{h}}$ & 1555 & 777.5 to 3110 \\
\hline 46 & Activation time constant, ms & $N-\tau_{\mathrm{m}}$ & 0.942 & 0.471 to 1.884 \\
\hline 47 & $V_{1 / 2}$ inactivation, $\mathrm{mV}$ & $N-V_{\mathrm{h}}$ & 39 & 35 to 44 \\
\hline 48 & $V_{1 / 2}$ activation, $\mathrm{mV}$ & $N-V_{\mathrm{m}}$ & 19.88 & 15 to 24 \\
\hline
\end{tabular}


Table 2. Constraints on measurements for declaring a model to be valid under the global sensitivity analysis paradigm

\begin{tabular}{lll}
\hline Measurement, unit & Lower bound & Upper bound \\
$f_{250}, \mathrm{~Hz}$ & 10 & 35 \\
$V_{\mathrm{AP}}, \mathrm{mV}$ & 90 & 110 \\
$R_{\text {in }}, \mathrm{M} \Omega$ & 50 & 90 \\
$|Z|_{\max }, \mathrm{M} \Omega$ & 50 & 110 \\
$f_{\mathrm{R}}, \mathrm{Hz}$ & 2 & 5.5 \\
$Q$ & 1.01 & 1.5 \\
$\Phi_{\mathrm{L}}$, rad.Hz & 0 & 0.15
\end{tabular}

These bounds were extracted from experimental recordings (somatic recordings) presented by Narayanan and Johnston $(2007,2008)$ and Narayanan et al. (2010).

\section{Self-regulation of calcium homeostasis}

To study activity-dependent self-regulation of calcium homeostasis in a hippocampal pyramidal neuron, we adapted the model introduced by O'Leary et al. (2014) based on the central dogma of molecular biology (Alberts et al., 2007). Specifically, we used a single transcription factor to regulate calcium-dependent transcription of the twelve channels expressed in the model neuron, with different time constants $\left(\tau_{i}\right)$ for the messenger RNA (mRNA) evolution associated with each channel $\left(m_{\mathrm{i}}\right)$ :

$$
\tau_{i} \dot{m}_{i}=\left[\mathrm{Ca}^{2+}\right]_{\text {tgt }}-\left[\mathrm{Ca}^{2+}\right]_{c}
$$

where $\left[\mathrm{Ca}^{2+}\right]_{\text {tgt }}$ (default value was $200 \mathrm{nM}$ ) represented the target value of cytosolic calcium concentration $\left(\left[\mathrm{Ca}^{2+}\right]_{C}\right)$ at which homeostasis should be maintained. The evolution of conductances $\left(g_{i}\right)$ of individual channels from their respective mRNA (translation) was governed by:

$$
\tau_{g} \dot{g}_{i}=m_{i}-g_{i}
$$

where $\tau_{g}$ is the time constant for the translational process, and was set to be identically equal to $10 \mathrm{~ms}$ for all 12 conductances. We noted, with an additional set of simulations, that changes to the specific value of $\tau_{g}$ merely altered the time-course toward reaching steady-state, but not the steady-state values of the conductances. For the mRNAs and the conductances to evolve as functions of the integral of error in calcium with reference to the target calcium (Eqs. 21, 22), we randomized the initial values of $m_{i}$ 's and $g_{i}$ 's to be very low. The time constants $\left(\tau_{i}\right)$ for the evolution of mRNAs with reference to each channel were selected from the corresponding conductances of the valid models obtained from the GSA. Specifically, the time constants $\left(\tau_{i}\right)$ for transcription were set to different values as follows (O'Leary et al., 2014):

$$
\frac{\tau_{j}}{\tau_{i}}=\frac{g_{i}^{k}}{g_{j}^{k}},
$$

where $i$ and $j$ correspond to the 12 ion channels in our model, and $k$ varies from 1 to 78 and corresponds to the number of valid models obtained from the GSA. As Eq. 23 defines $\tau_{i}$ ratios from $g_{i}$ ratios, one of the $\tau_{i}$ values needed to be set to obtain the other values. We set the $\tau_{i}$ value associated with the sodium conductance at $10 \mathrm{~ms}$, and computed the other $\tau_{i}$ values from the appropriate con- ductance ratios as in Eq. 23. We noted, with an additional set of simulations, that changes to the specific value of the $\tau_{i}$ value for the sodium channel altered the time-course toward reaching steady-state, but not the steady-state values of the conductances. The temporal evolution of transcription and translation were independently assessed for each of the 78 valid models by setting the $\tau_{i}$ values to be dependent on the corresponding conductance ratios in each of these models (O'Leary et al., 2014). The other parameters associated with the model (the half-maximal activation voltages, time constants of ion channels and passive properties) were all derived from the respective valid model from where the $\tau_{i}$ values were derived from.

\section{Assessing state-dependent evolution of calcium homeostasis}

In a manner similar to conditions observed under in vivo conditions, changes in afferent input to the neuron were presented as changes to synaptic receptors, specifically to AMPAR and NMDAR permeabilities (Eqs. 2-9). We tested the evolution of calcium homeostasis with two different types of afferent activity patterns that correspond to different behavioral states. The first corresponded to inputs received by hippocampal neurons during awake/REM-sleep state, and were modeled using a theta frequency $(8 \mathrm{~Hz})$ sinusoidal modulation (Buzsáki et al., 1983; Harvey et al., 2009) of AMPAR/NMDAR permeabilities (Fig. 7B). The amplitude of the sinusoidal permeability modulation was such that it was the minimum amplitude required to elicit action potentials in the neuron.

The second type of afferent activity pattern reflected that during non-exploratory/non-REM sleep state (Fig. $7 C)$, where the neuron received SWRs riding on largely silent periods (Buzsáki, 1986). The shape of the SWR waveform was derived from English et al. (2014), and SWR amplitude was set such that the response to an SWR input resulted in a membrane voltage change of 2-10 mV (English et al., 2014). Specifically, the functional form of SWR inputs was modeled as follows:

$$
\begin{aligned}
& \operatorname{SWR}(t)=\exp \left(-\frac{(t-55)^{2}}{2 \times 20 \times 20}\right)-0.3 \\
& \exp \left(-\frac{(t-40)^{2}}{2 \times 15 \times 15}\right) \sin \left(2 \pi f_{\text {ripple }} t / 1000\right),
\end{aligned}
$$

where $t$ represented time in milliseconds, and $f_{\text {ripple }}$ was the ripple frequency set at $150 \mathrm{~Hz}$. Each SWR waveform lasted for around $150 \mathrm{~ms}$, and was set to repeat at $3 \mathrm{~Hz}$ (Buzsáki, 1986; English et al., 2014). Afferent activity of the same type was continued until steady state of evolution in conductances (Eq. 22) was achieved (typically around $150 \mathrm{~s}$ ), at which point measurements of intrinsic properties were noted and a switch in afferent activity was effectuated as necessary. All switches in afferent activity from theta oscillations to SWR inputs were initiated after a reset pulse to $-65 \mathrm{mV}$ for $1 \mathrm{~s}$ to avoid depolarizationinduced block observed in certain neurons. 


\section{Simulation details}

All simulations were performed in the NEURON simulation environment (Carnevale and Hines, 2006) at $-65 \mathrm{mV}$ and $35^{\circ} \mathrm{C}$ with an integration time constant of $25 \mu \mathrm{s}$. Temperature dependence of channel kinetics was appropriately accounted for with experimentally measured $Q_{10}$ values for each channel. The computational complexity of these simulations was enormous, as there were several differential equations associated with the activation and inactivation gates of the 11 ion channels (excluding the leak channel), the differential equation for the voltage and calcium (including calcium diffusion; Eqs. 10-17), and the differential equations governing the evolution of $12 \mathrm{mR}$ NAs and 12 conductances (Eqs. 21-23). The solutions to all these differential equations were computed at every time step (of $25 \mu \mathrm{s}$ ) over a period of $150 \mathrm{~s}$ in achieving steady state for one type of afferent activity (a double switch in afferent activity is $>3 \times 150=450 \mathrm{~s}$, running for several days in terms of simulation time), for each of the 78 valid models. Data analyses were performed using custom-written code with IGOR Pro (Wavemetrics) and statistical analyses were performed with the R Statistical Package (R Core Team, 2014).

\section{RESULTS}

\section{Generation of a valid model population through global sensitivity analysis}

As a first step in assessing state-dependence of cellautonomous calcium homeostasis in hippocampal neurons, we generated several biophysically realistic models of CA1 pyramidal neurons using the GSA approach. Specifically, we created a cylindrical base neuronal model $(100 \times 100 \mu \mathrm{m})$ containing 12 ion channels (Leak, NaF, $\mathrm{KDR}, \mathrm{KA}, \mathrm{KM}, \mathrm{HCN}, \mathrm{CaL}, \mathrm{CaT}, \mathrm{CaN}, \mathrm{CaR}, \mathrm{BK}$, and SK) and AMPA and NMDA receptors (Fig. $1 A$ ). We hand-tuned the base model such that the seven intrinsic measurements namely, $f_{250}, V_{\mathrm{AP}}, R_{\text {in }},|Z|_{\text {max }}, f_{\mathrm{R}}, Q$, and $\Phi_{\mathrm{L}}$ (Fig. $1 B-H)$ were within experimentally determined ranges (Narayanan and Johnston, 2007, 2008; Narayanan et al., 2010). We then uniformly sampled 48 parameters (spanning passive properties and densities/kinetics of channels in the neuron) from a range determined from the corresponding base model values to generate 4000 neurons (Table 1). We obtained seven measurements from each of these 4000 model neurons, and compared the measurements against their experimental counterparts. A model neuron was declared valid if all seven measurements of the model fell within their respective experimental bounds (Table 2). Upon imposing these experimental constraints on measurements from the 4000 models, we found 78 $(\sim 2 \%)$ models to be valid. To test whether there were correlations between channel expression profiles and their kinetics, we asked whether there were pairwise correlations between the values of the 48 parameters associated with these 78 valid models. Consistent with previous results on hippocampal neurons (Rathour and Narayanan, 2012a, 2014), we found the parametric values to be weakly correlated (Fig $2 A$ ) with the range of correlation coefficients ranging from -0.6 to 0.6 (Fig $2 B-C$ ). Importantly, of the 1128 correlation coefficients, 1125 were in the range of -0.4 to 0.4 suggesting weak pairwise relationships between parameters in the model. As the 78 models were valid models (referred to as GSA models in what follows) for hippocampal pyramidal neuron physiology, we used these for our analysis on state-dependence of intrinsic properties in regulating calcium homeostasis.

\section{Under theta-frequency afferent activity, calcium- dependent evolution of ionic conductances resulted in variable plasticity of intrinsic properties}

We set the time constants $\left(\tau_{i}\right)$ for the evolution of mRNAs with reference to each channel from the corresponding conductances obtained from the valid model (Eq. 23), and implemented the evolution of calcium homeostasis (Eqs. $21,22)$ for each of the 78 valid models. The neurons were presented with theta-frequency afferent activity, modeled as an $8 \mathrm{~Hz}$ sinusoidal permeability change in synaptic receptors. The mRNAs and conductances were allowed to evolve in time until a steady state was achieved in the cytosolic calcium concentration and the conductance values (Fig. $3 A$ ). During the initial phase of the evolution process, the voltage response of the model neuron to the sinusoidal input conductance corresponded to largeamplitude oscillations with small action potential amplitudes (Fig. 3A). We noted that this was consequent to the initial low values of all conductances, implying a large input resistance leading to large-amplitude voltage oscillations. The small action potential amplitudes, on the other hand, were consequent to the lower values of the spike-generating fast sodium conductance. As the calcium-dependent evolution progressed toward achieving the target calcium value, the voltage response corresponded to large-amplitude action potentials within each theta cycle (Fig. $3 A$ ).

Although the overall patterns of voltage evolution across the 78 models were similar to the example presented in Fig. $3 A$, there was significant variability in the final steady-state firing behavior of the model. Specifically, there was variability in the number of action potentials fired per cycle and there were models that did not fire at every cycle of the theta, with some of them exhibiting skipping spikes in alternate cycles and others skipping several cycles (Fig. 3B). These results imply that the maintenance of calcium homeostasis does not require and does not translate to maintenance of firing rate homeostasis, thereby establishing the dissociation between activity homeostasis and calcium homeostasis.

As neuronal firing properties are dictated by ionic conductances, we asked whether changes in conductance values during theta-dependent evolution was also variable. To answer this, we plotted the histogram of sodium conductances obtained after theta-dependent evolution for the 78 valid models, and found that the variability in firing patterns also reflected in these conductance values (Fig. 3C). We plotted the histogram solely for the sodium conductance, and not for all 12 conductances because the changes in all conductances are correlated given that a single transcription factor regulated all conductances (O'Leary et al., 2014; Eqs. 21-23; Fig. 3A). These results imply that the maintenance of calcium homeostasis does 


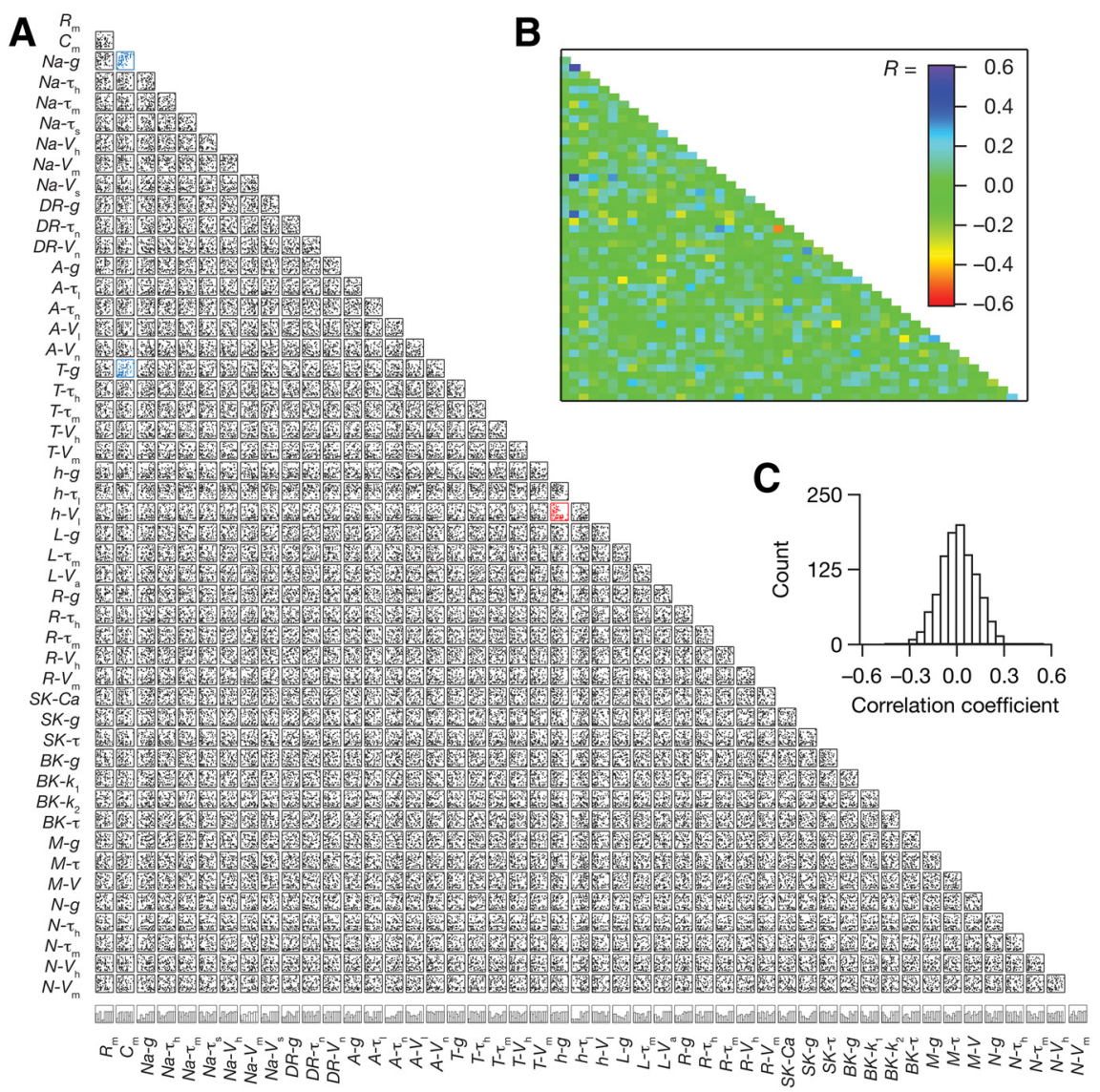

Figure 2. Weak correlations between underlying parameters in valid models that emerged from global sensitivity analysis spanning 48 parameters. A, Pairwise interactions of the 48 parameters of the valid model population consisting of 78 models. Blue scatter plots represent parametric pairs whose correlation coefficient was more than 0.4 , whereas red scatter plots indicate pairs with correlation coefficient less than - 0.4. Bottom, The normalized histograms of the 48 parameters across the 78 valid models. $\boldsymbol{B}$, Color-coded plot denoting the correlation coefficients for the corresponding scatter plots in $\boldsymbol{A}$. $\boldsymbol{C}$, Histogram of the 1128 correlation coefficients corresponding to the scatter plots in $\boldsymbol{A}$.

not require and does not translate to maintenance of individual channels at specific conductance values, thereby establishing the dissociation between individual channelostasis (Rathour and Narayanan, 2014) and calcium homeostasis (O'Leary et al., 2014).

Variability in the percentage change in conductance values would imply that the intrinsic response properties of the neuron should have undergone variable plasticity during the evolution of calcium-dependent homeostasis. Therefore, we calculated the seven intrinsic measurements at steady state of the $\theta$-dependent evolution, and compared these measurements with their corresponding GSA values for each of the 78 valid models. We found that $\theta$-dependent evolution introduced variable plasticity in each of these measurements, with significant variability in the strength and sign of these changes (Fig. 3D). Importantly, although the conductance values obtained from GSA were those that satisfied experimental bounds (Table 2), several measurement values at steady state after $\theta$-dependent evolution were not valid with reference to these experimental bounds (Fig. 3D). Together these results revealed that plasticity in neuronal intrinsic properties and in conductances could exhibit significant vari- ability when ionic conductances were allowed to evolve toward achieving calcium homeostasis with $\theta$-oscillations as afferent inputs. These results imply that the mere maintenance of calcium homeostasis does not require and does not translate to maintenance of intrinsic measurements within a "valid" range, thereby establishing the dissociation between functional homeostasis and calcium homeostasis.

\section{Sensitivity of intrinsic plasticity driven by calcium homeostasis to target calcium concentration and to the strength and frequency of afferent activity}

What was the impact of changing the target calcium concentration, $\left[\mathrm{Ca}^{2+}\right]_{\text {tgt }}$ (from the default value of $200 \mathrm{nM}$ ), on the temporal evolution of conductances and consequent plasticity in intrinsic properties? To address this, we repeated the $\theta$-dependent evolution experiments (Fig. 3) with two other values for $\left[\mathrm{Ca}^{2+}\right]_{\text {tgt }}$, set at 100 and $300 \mathrm{~nm}$. We observed neuronal firing at steady state $(150 \mathrm{~s})$ of $\theta$-dependent evolution and found that the neuronal model fired more action potentials per $\theta$-cycle upon increase in $\left[\mathrm{Ca}^{2+}\right]_{\text {tgt. }}$. However, at a higher target value $(300 \mathrm{nM})$, the neuron entered into depolarization-induced block with the 
A
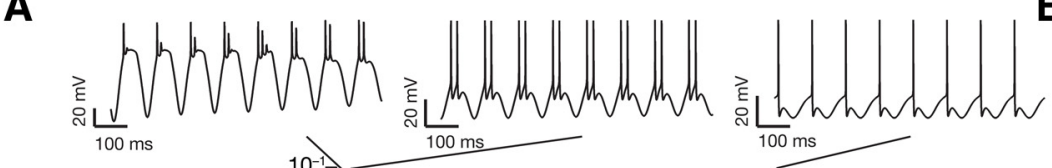

B
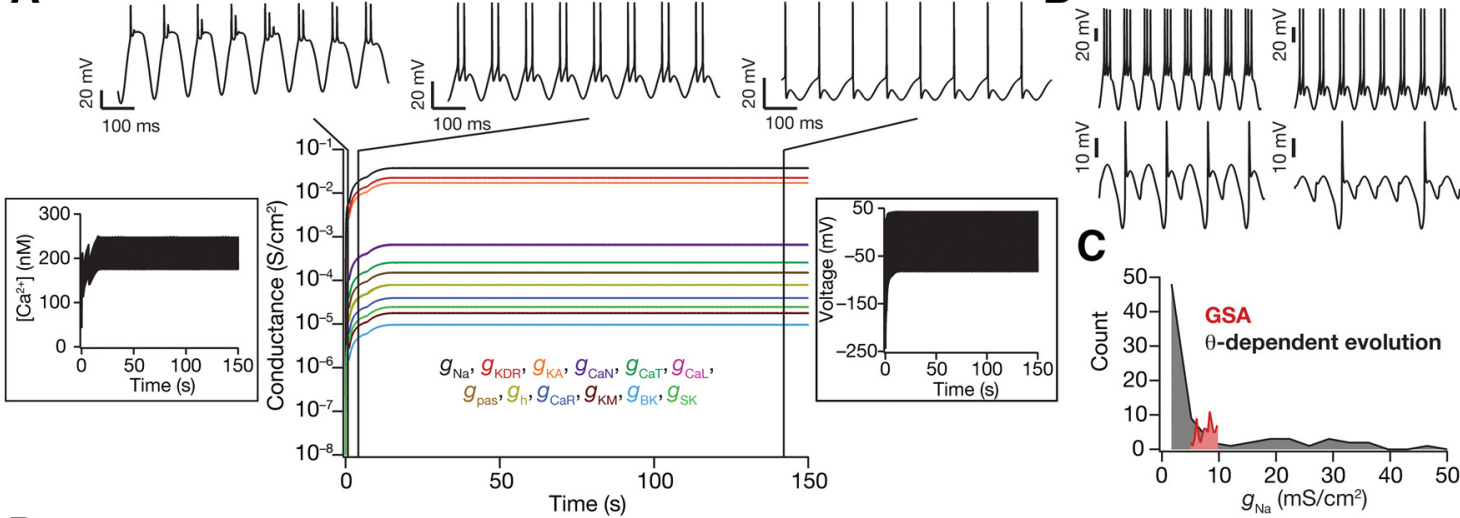

D
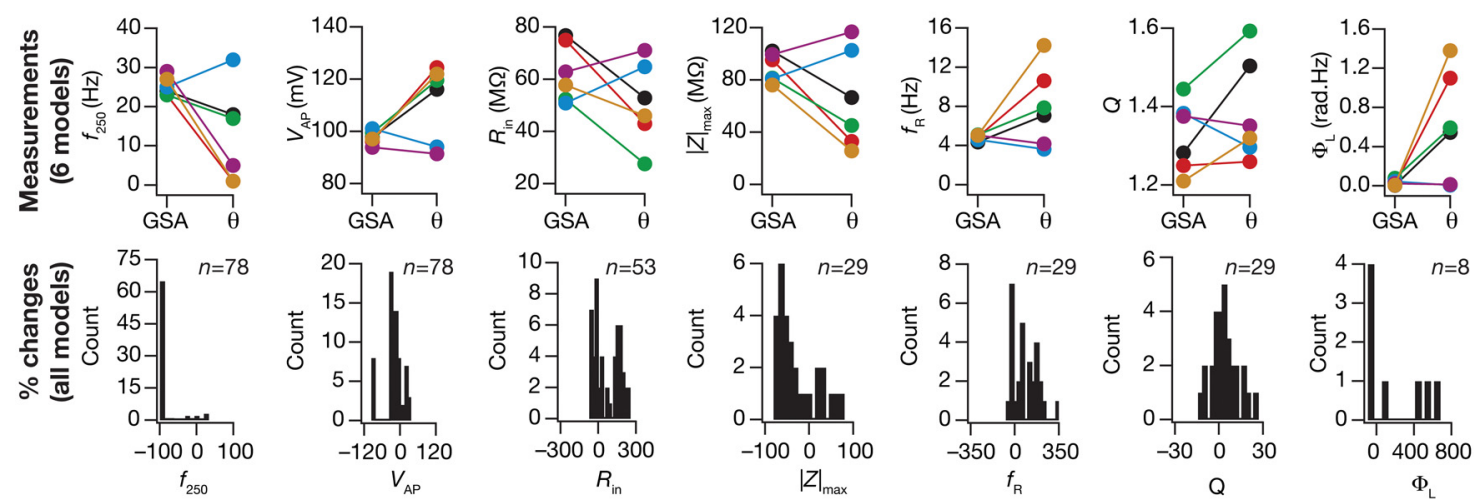

Figure 3. Evolution of ionic conductances and intrinsic measurements through cell-autonomous self-regulation of calcium homeostasis in model neurons receiving theta-frequency inputs. $\boldsymbol{A}$, Temporal evolution of the internal calcium concentration (left), the 12 ionic conductances in the model (Leak, NaF, KDR, KA, KM, HCN, CaL, CaN, CaR, CaT, BK, SK; middle) and membrane voltage (right) in a model neuron receiving sinusoidal input of $8 \mathrm{~Hz}$. The firing pattern of the neuron is shown at the three different temporal locations (middle). $\boldsymbol{B}$, Firing pattern of four different model neurons at steady-state of theta-dependent evolution. All traces are for a $1 \mathrm{~s}$ period. $\boldsymbol{C}$, Histogram of $g_{\mathrm{Na}}$ measured at steady state of evolution with $\theta$-frequency oscillations (black). Also plotted is the histogram of base values of $g_{\mathrm{Na}}$ obtained from GSA. Histograms are across the 78 valid models. $\boldsymbol{D}$, Top, Seven intrinsic measurements $\left(f_{250}, V_{\mathrm{AP}}, R_{\mathrm{in}},|Z|_{\text {max }}, f_{\mathrm{R}}, Q, \Phi_{\mathrm{L}}\right)$ at steady state of theta-dependent evolution $(\theta)$ of six different valid models (color-coded) compared with the corresponding baseline GSA values (GSA). Bottom, Histograms of the percentage change in the seven measurements at steady state of theta-dependent evolution from the corresponding baseline GSA values, plotted for all 78 valid models. Percentage change in subthreshold measurements $\left(R_{\mathrm{in}},|Z|_{\text {max }}, f_{\mathrm{R}}, Q\right.$, $\Phi_{\perp}$ ) were computed only for those models that did not fire action potentials in response to the injected stimulus. In addition, models that showed very high percentage changes in $\Phi_{\mathrm{L}}$ were eliminated. The number of models $(n)$ used for each histogram is mentioned in the respective panel.

membrane potential hovering at suprathreshold voltagelevels (Fig. 4A). Turning to steady-state values of intrinsic properties after $\theta$-dependent evolution, we noted that variable plasticity in all seven intrinsic measurements was observed across all three values of $\left[\mathrm{Ca}^{2+}\right]_{\mathrm{tg}}$, with no qualitative differences observed in measurement variability with different values of $\left[\mathrm{Ca}^{2+}\right]_{\text {tgt }}$ (Fig. $\left.4 B-H\right)$.

We next assessed the impact of afferent activity strength on $\theta$-dependent evolution by altering the peakto-peak amplitude of the sinusoidal modulation in receptor permeability, with the sinusoidal frequency fixed at 8 $\mathrm{Hz}$ (Fig. 5). Whereas the neuron did not fire action potentials for lower strengths of afferent input (Fig. $5 A$; permeability value $P_{1}$ ), at very high values of input permeability neurons entered into depolarization-induced block with average membrane potential around $-30 \mathrm{mV}$ (Fig. 5A; permeability value $P_{4}$ ). In the mid-range between these two extremes, the number of action potentials fired per cycle increased with increase in afferent input strength. Assessing steady-state values of intrinsic properties after $\theta$-dependent evolution, we noted that variable plasticity in all seven intrinsic measurements was observed across all tested values of input strength, with no qualitative differences observed in the measurement variability with different values of the sinusoidal peak-to-peak amplitude (Fig. 5B-H).

Finally, to understand the impact of afferent activity beyond the theta-frequency range on the evolution of calcium homeostasis and intrinsic properties, we picked samples from different frequency bands (delta: $1 \mathrm{~Hz}$, theta: $8 \mathrm{~Hz}$, slow gamma: $40 \mathrm{~Hz}$, and fast gamma: $100 \mathrm{~Hz}$ ) and repeated our simulations (until steady-state was achieved) with these afferent input frequencies. Neuronal response reflected theta-frequency band-pass structure of hippocampal pyramidal neurons, eliciting maximal firing response at the theta range with reduced response 
A
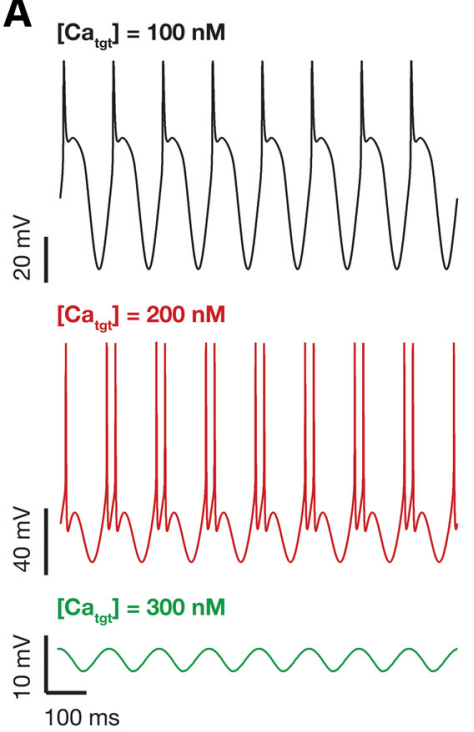

$\mathbf{F}$

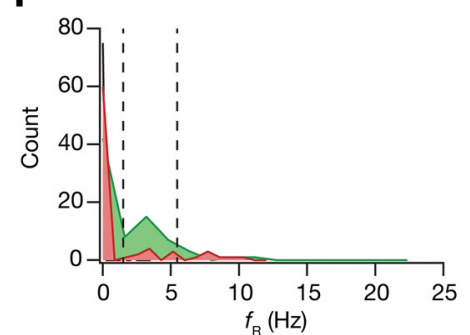

B

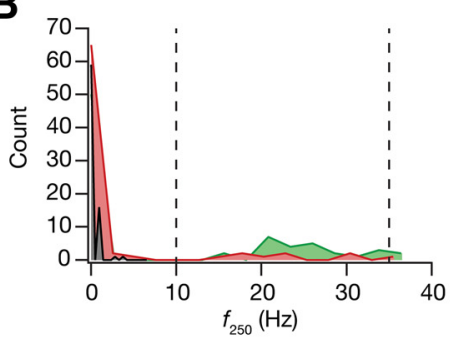

D

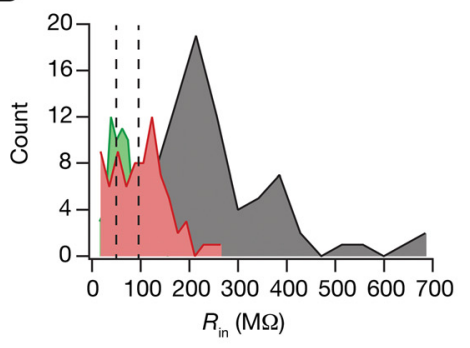

G

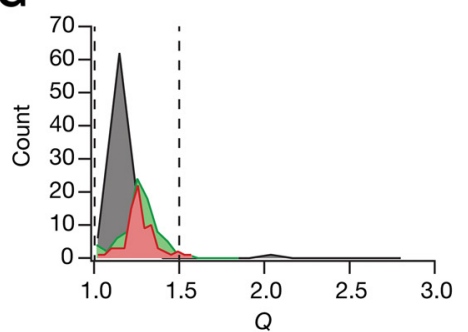

C

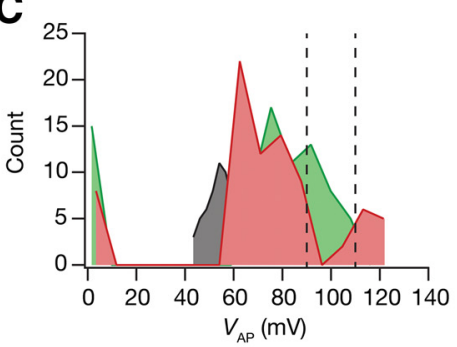

E

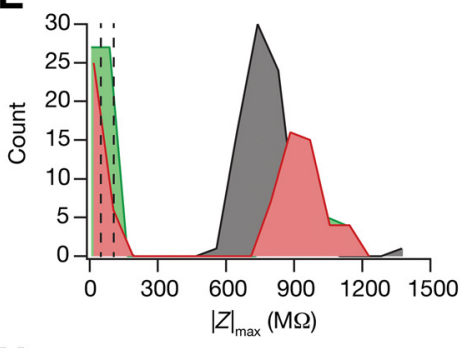

H

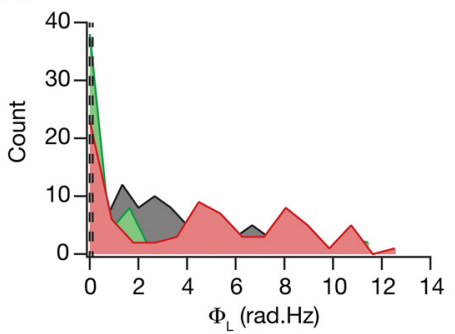

Figure 4. The target value of internal calcium concentration critically regulated changes in intrinsic response properties during cell-autonomous self-regulation of calcium homeostasis. $\boldsymbol{A}$, The steady-state voltage response after theta-dependent evolution plotted for three different target calcium levels (black, 100 nм; red, 200 nм; green, 300 nм). $\boldsymbol{B}-\boldsymbol{H}$, Histograms of the steady-state measurement values $\left(f_{250}, \boldsymbol{B} ; V_{\mathrm{AP}}, \boldsymbol{C} ; R_{\mathrm{in}}, \boldsymbol{D} ;|Z|_{\max }, \boldsymbol{E} ; f_{\mathrm{R}}, \boldsymbol{F} ; \boldsymbol{Q}, \boldsymbol{G} ; \Phi_{\mathrm{L}}, \boldsymbol{H}\right)$ for the 78 valid models, obtained after theta-dependent evolution with different target calcium levels. The dashed lines in $B-H$ represent the lower and upper bounds for the corresponding measurement (in that order) in the GSA model validation procedure (Table 2).

with little or no firing at other frequency bands (Fig. 6A). Although the measurements at steady state of calciumdependent evolution did exhibit significant variability across the 78 models, their values did not have any specific dependence on the frequency of the input (Fig. $6 B-H)$. For all further analyses, the default input frequency was $8 \mathrm{~Hz}$ to take into account the hippocampal theta rhythms, as mentioned above. Together, although neuronal firing pattern was heavily dependent on target calcium values and the strength/frequency of afferent inputs, intrinsic properties measured across all parametric combinations exhibited significant variability in the plasticity consequent to calcium-dependent evolution of conductances.

\section{Neuronal conductances exhibited differential robustness to an intervening switch in the type of afferent activity}

To study the state dependence of such a calcium homeostatic mechanism, we used experimentally well established differences in afferent activity to hippocampal neurons during different behavioral states and during different modules of the sleep cycle (Buzsáki, 2006; Miz- useki et al., 2011; Grosmark et al., 2012). Specifically, during REM sleep or exploratory behavior, afferent activity to the hippocampal CA1 neuron is dominated by oscillations in the theta-frequency (Fig. $7 B$ ), whereas during non-REM or non-exploratory behavior, the neuron predominantly receives SWRs riding on largely silent background (Fig. 7C). In this context, to study state dependence of the autonomous self-regulating calcium homeostasis mechanism, we switched the afferent activity to the neuron between $\theta$-frequency oscillations and SWR activity. We analyzed two different temporal sequences of activity: theta-SWR-theta and SWR-thetaSWR sequences (Fig. 7A), with each afferent state of activity lasting for $150 \mathrm{~s}$ (to achieve steady-state conductance values with each phase of afferent activity).

Given the formulation of the dynamical evolution, the calcium levels expectedly converged to the target value of calcium, with transient changes occurring during the period that followed the switches. This maintenance of calcium homeostasis was effectuated by alterations in ionic conductances, which accommodated for the switch in afferent activity patterns (Fig. 7D-F). Although the extent of plasticity in ionic conductances was a continuum (see 
A
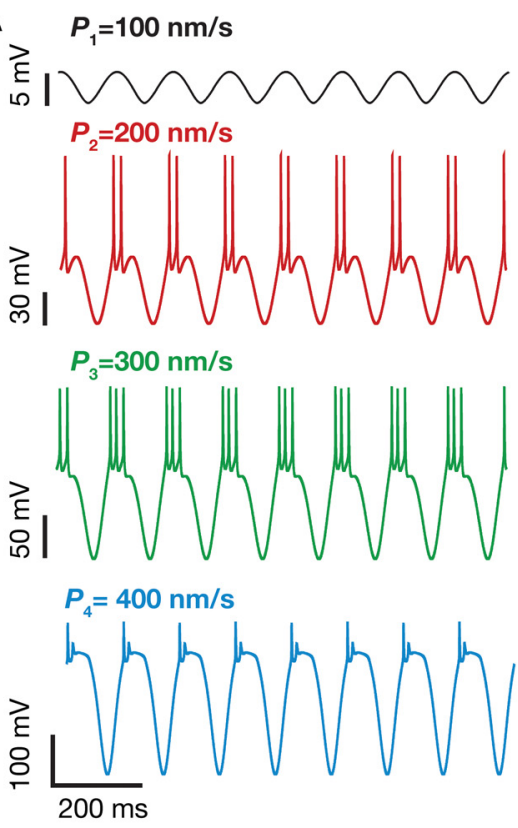

$\mathbf{F}$

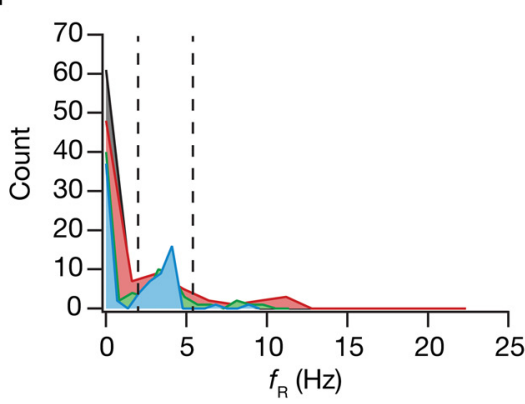

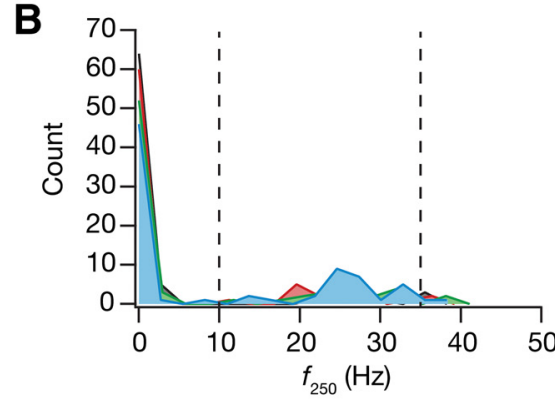

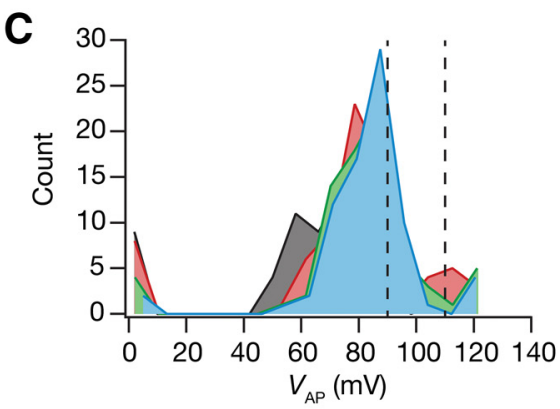

D

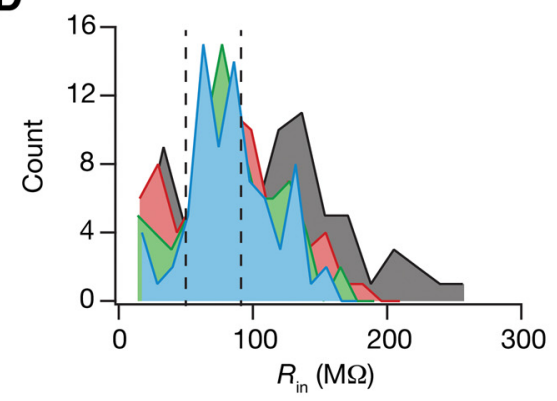

G

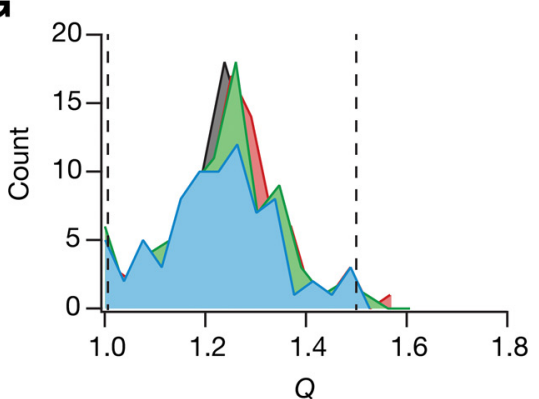

E

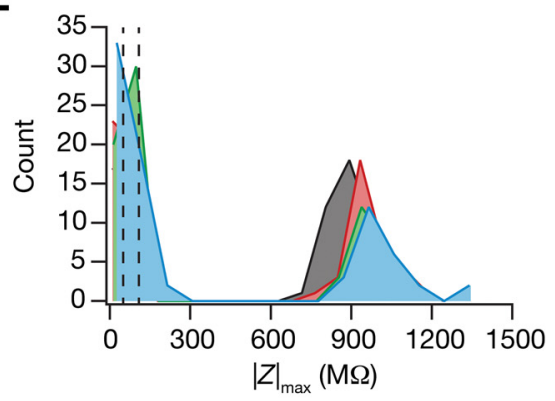

H

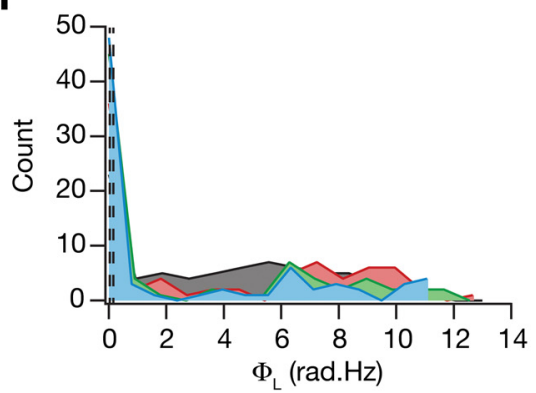

Figure 5. The strength of afferent theta inputs critically regulated changes in intrinsic response properties during cell-autonomous self-regulation of calcium homeostasis. $\boldsymbol{A}$, The steady state voltage response after theta-dependent evolution, for four different amplitudes of the $8 \mathrm{~Hz}$ input sinusoid (peak-to-peak value of sinusoidal permeability: black, $100 \mathrm{~nm} / \mathrm{s}$; red, $200 \mathrm{~nm} / \mathrm{s}$; green, $300 \mathrm{~nm} / \mathrm{s}$; blue, $400 \mathrm{~nm} / \mathrm{s}$ ). Note that at high values of sinusoidal amplitudes (e.g., $400 \mathrm{~nm} / \mathrm{s}$ ) the deflections are large along the hyperpolarized direction because of the large driving force for AMPA/NMDA receptors that mediate the sinusoidal oscillations. Along the depolarized direction, an action potential was elicited once the membrane potential crossed threshold, and the amplitude of the action potential did not cross the sodium reversal potential of $+55 \mathrm{mV}$. $\boldsymbol{B}-\boldsymbol{H}$, Histograms of the steady state measurement values $\left(f_{250}, \boldsymbol{B} ; V_{\mathrm{AP}}, \boldsymbol{C} ; R_{\mathrm{in}}, \boldsymbol{D} ;|Z|_{\mathrm{max}}, \boldsymbol{E} ; f_{\mathrm{R}}, \boldsymbol{F} ; \boldsymbol{Q}, \boldsymbol{G} ; \Phi_{\mathrm{L}}\right.$, $\boldsymbol{H})$ for the 78 valid models, obtained after theta-dependent evolution with different sinusoidal amplitudes. The dashed lines in $B-H$ represent the lower and upper bounds for the corresponding measurement (in that order) in the GSA model validation procedure (Table 2).

below), we classified neurons into two distinct classes based on the amount of plasticity in ionic conductances. The first corresponded to neurons that underwent significant plasticity in their conductance values upon receiving the same type of afferent activity after an intervening period of switch to a different activity pattern (plastic neurons, $\sim 80 \%$; Fig. $7 D, F$ ). A second class of neurons restored their conductance values, exhibiting similar values upon receiving the same type of afferent activity after an intervening period of switch to a different activity pattern (robust neurons, 20\%; Fig. 7E,G). Concurrently, neuronal response (firing) patterns with identical afferent activity were similar in robust neurons (Fig. $7 E, G$ ), but were significantly different in plastic neurons (Fig. 7D).

We assessed the percentage changes in sodium conductance after each switch in both sequences (across all
78 model neurons), and found that the changes in conductances introduced by the switches were significantly variable (Fig. $8 B-E$ for the theta-SWR-theta sequence and $\mathrm{G}-J$ for the SWR-theta-SWR sequence). We plotted the histogram solely for the sodium conductance, but not for all 12 conductances because the changes in all conductances are correlated given that a single transcription factor regulated all conductances. However, upon reverting back to the same type of afferent activity, a significant percentage of neurons were robust (with reference to conductance values, firing patterns and intrinsic properties) to the intervening switch to another type of afferent activity (Fig. $8 E, J$ ). The robustness of the neuron to an intermediate activity switch, however, was dependent on the specific temporal sequence of activity switch. Specifically, the percentage of neurons robust to an intervening 
A
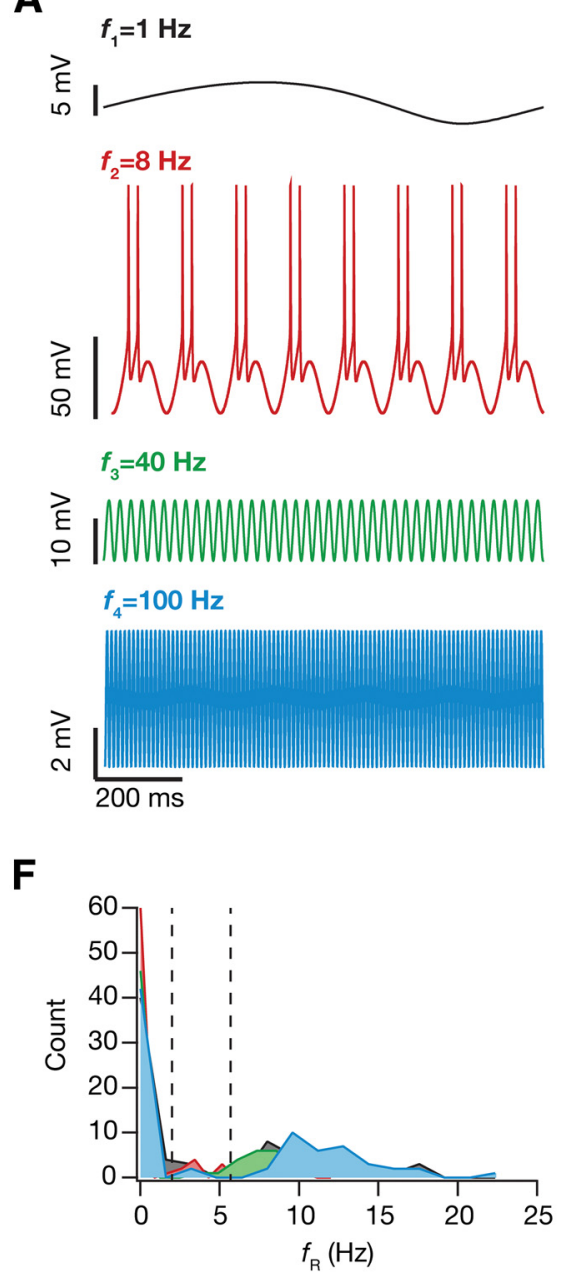

B

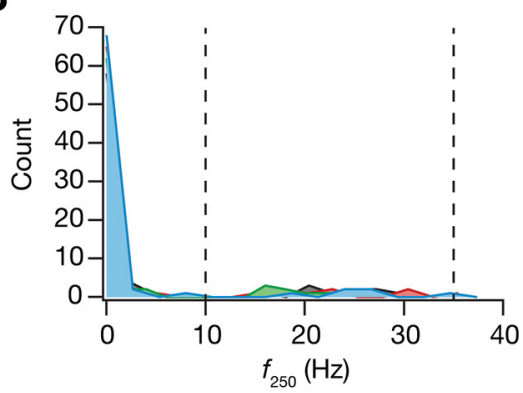

D

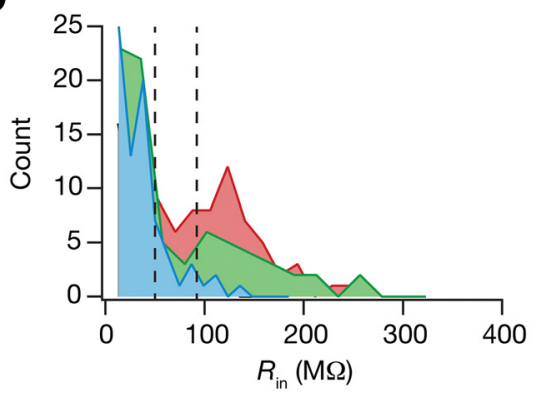

G

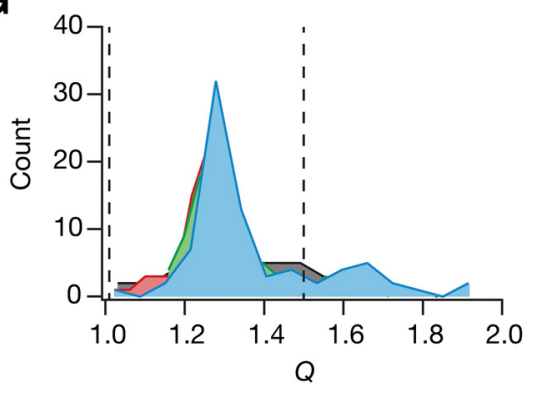

C

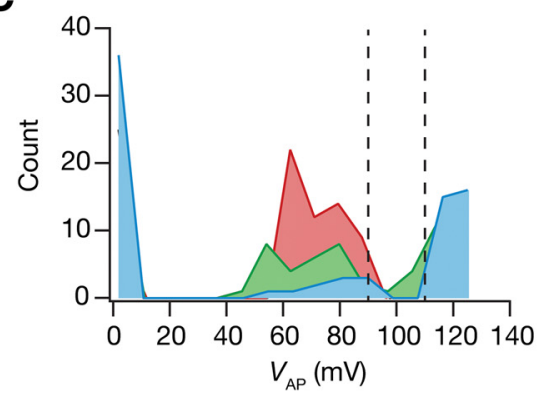

E

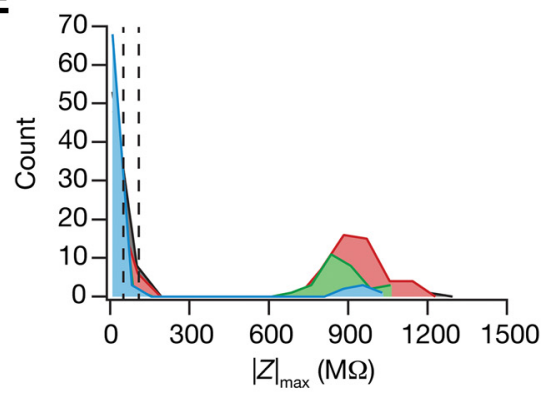

H

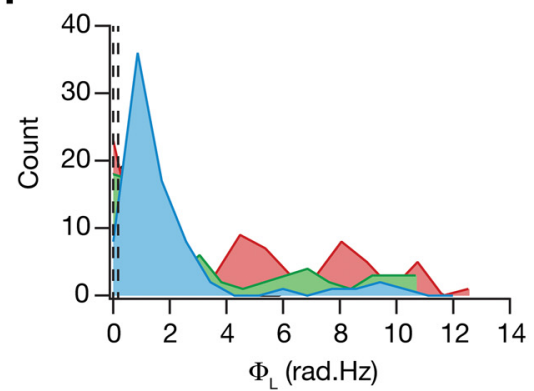

Figure 6. The frequency of afferent inputs critically regulated changes in intrinsic response properties during cell-autonomous self-regulation of calcium homeostasis. $\boldsymbol{A}$, The steady state voltage response for 4 different sinusoidal frequencies (delta, $1 \mathrm{~Hz}$, black; theta, $8 \mathrm{~Hz}$, red; slow gamma, $40 \mathrm{~Hz}$, green; fast gamma, $100 \mathrm{~Hz}$, blue). $\boldsymbol{B}-\boldsymbol{H}$, Histograms of the steady state measurement values $\left(f_{250}, \boldsymbol{B} ; V_{\mathrm{AP}}, \boldsymbol{C} ; R_{\mathrm{in}}, \boldsymbol{D} ;|Z|_{\max }, \boldsymbol{E} ; f_{\mathrm{R}}, \boldsymbol{F} ; \boldsymbol{Q}, \boldsymbol{G} ; \Phi_{\mathrm{L}}, \boldsymbol{H}\right)$ for the 78 neurons for different sinusoidal frequencies appropriately color-coded. The dashed lines in $B-H$ represent the lower and upper bounds for the corresponding measurement (in that order) in the GSA model validation procedure (Table 2).

period of activity switch was lower for the theta-SWRtheta ( $20 \%$; Fig. $8 E$ ) compared with the percentage for SWR-theta-SWR sequence ( $90 \%$; Fig. $8 \mathrm{~J})$. These results also reveal that the maintenance of calcium homeostasis does not necessarily require or translate to maintenance of individual conductances at specific values (O'Leary et al., 2014), and that significant plasticity in ionic conductances need not necessarily translate to significant changes in afferent-driven firing activity (Fig. 7F), thereby revealing a significant dissociation between individual channelostasis, activity/functional homeostasis and calcium homeostasis.

\section{Neuronal intrinsic properties exhibited differential robustness to an intervening switch in the type of afferent activity}

Finally, we asked how state-dependent evolution of calcium homeostasis altered neuronal intrinsic proper- ties. To do this, we measured seven intrinsic properties (Fig. 1) at steady states of temporal evolution with activity pattern (theta or SWR) with the theta-SWRtheta (Fig. 9) and the SWR-theta-SWR (Fig. 10) sequences. Analysis of the evolution of intrinsic properties with switch in afferent activity revealed several important observations. First, intrinsic properties underwent significant plasticity as a consequence of these switches in types of afferent activity, and the sign and strength of this plasticity varied across different model neurons. Second, in the process of such activitydependent evolution, neuronal intrinsic properties did not necessarily fall into their established experimental bounds (Figs. 9, 10; Table 2). These results reveal a significant dissociation between functional and calcium homeostasis. Third, when neurons were presented with identical (the initial pattern preceding the switch) activity patterns after an intervening period of switch in 
A

\begin{tabular}{|c|c|c|c|}
\hline GSA & Theta & SWR & Theta \\
\hline model & SWR & Theta & SWR \\
\hline
\end{tabular}

B

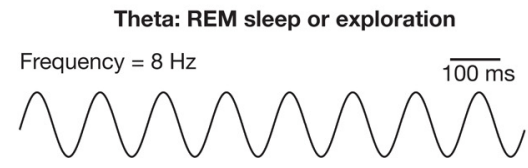

C

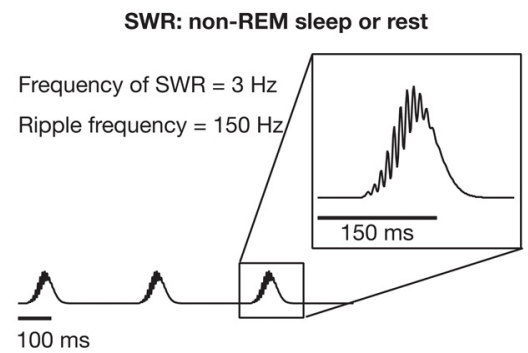

E

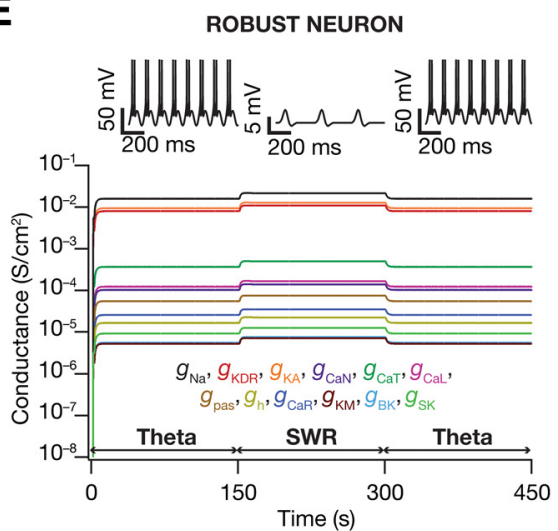

G

F
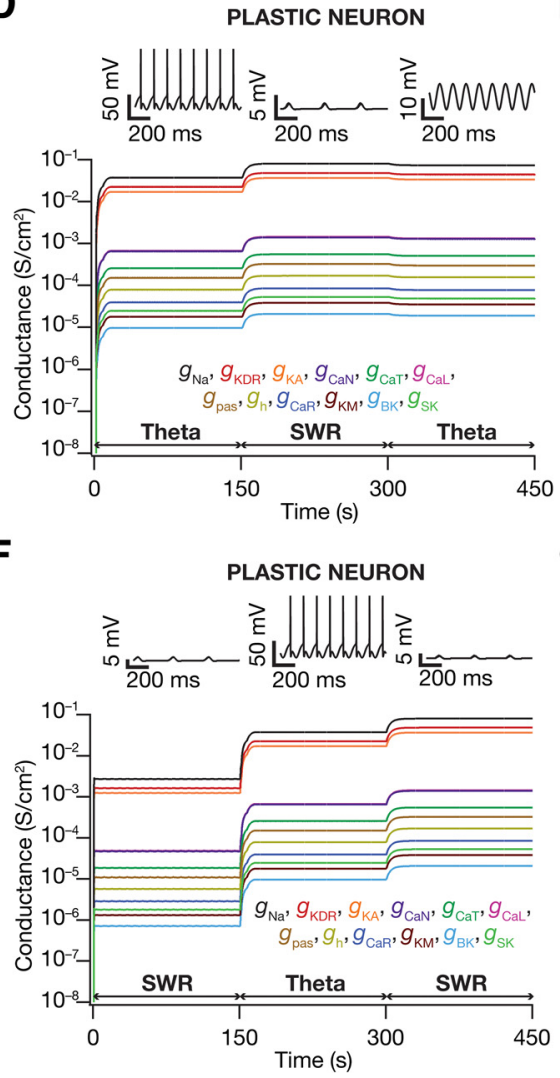

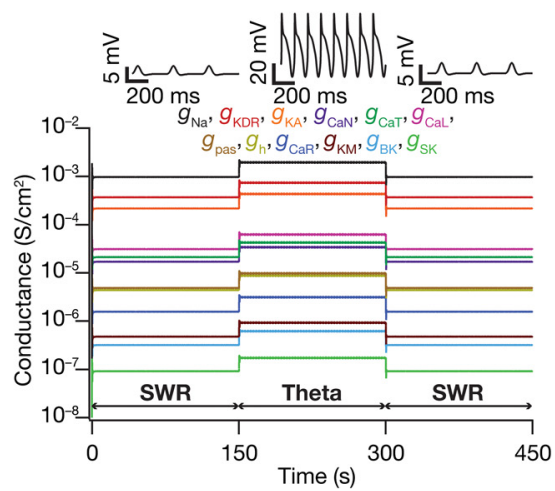

Figure 7. Switch in afferent activity between $\theta$ oscillations and SWRs triggered significant changes in ionic conductances during cell-autonomous self-regulation of calcium homeostasis. A, Experimental design for assessing state-dependence of ionic conductances during cell-autonomous self-regulation of calcium homeostasis. For each valid neuronal model obtained from GSA, ionic conductances were allowed to evolve toward achieving calcium homeostasis when afferent inputs were $\theta$ oscillations (or SWRs). At steady state of this evolution (150 s), inputs were switched to SWR (or $\theta$ oscillations). When this evolution reached steady state (150 $\mathrm{s}$ from the first switch), the input was switched back to $\theta$ oscillations (or SWR). $\boldsymbol{B}$, Input received by a neuron during awake/REM sleep state was modeled as theta-frequency oscillations $(8 \mathrm{~Hz})$ injected as AMPAR and NMDAR permeabilities. $\boldsymbol{C}$, Input received by a neuron during non-exploratory/non-REM sleep state was modeled as SWR inputs (inset, ripple frequency $f_{\text {ripple }}$ was $150 \mathrm{~Hz}$; Eq. 24), repeating at a frequency of $3 \mathrm{~Hz}$. These inputs were injected as AMPAR and NMDAR permeabilities into the neuronal model. $\boldsymbol{D}, \boldsymbol{E}$, Temporal evolution of the 12 ionic conductances in two different model neurons, where afferent activity switched from $\theta$ oscillations to SWR and back to $\theta$ oscillations. The calcium concentration (target [Ca]: $200 \mathrm{nM}$ ) and the conductances were allowed to reach steady state before either of the switches. The firing patterns of the neuron at the three steady states are also shown. F, G, Same as $\boldsymbol{D}, \boldsymbol{E}$, but with afferent activity switching from SWR to $\theta$ oscillations and back to SWR.

activity type, there were models whose intrinsic measurements did not restore to values before the intervening period. However, a significant proportion of neurons were robust to the intervening period of activity switch, where their intrinsic properties were restored when the activity pattern was switched back (Fig. 11). Similar to our observation with conductances, we noted that the percentage of neurons robust (in terms of changes in measurements) to an intervening period of activity switch was lower for the theta-SWR-theta (Fig. $11 A-G$ ) compared with the percentage for SWR-thetaSWR sequence (Fig. $11 \mathrm{H}-\mathrm{N}$ ). We also noted that neurons fired significantly higher during the theta periods and lesser during SWR periods, which was partly due to overall reduction in intrinsic excitability of the neurons during SWR period (Figs. 7-11). 

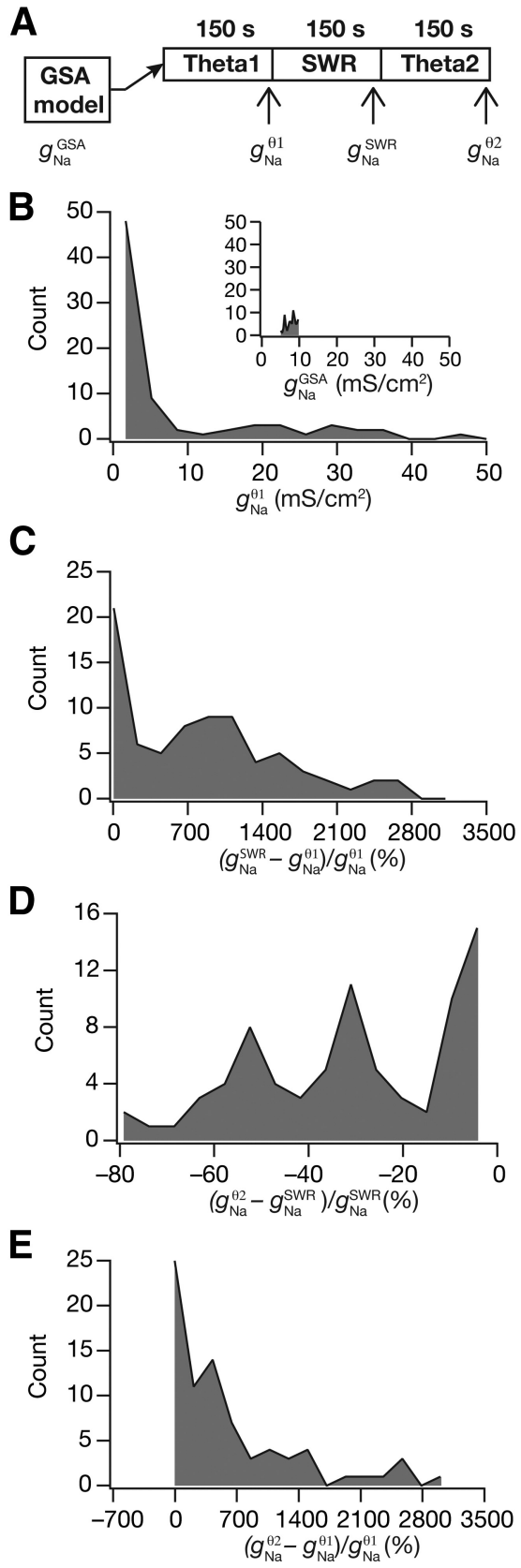

F

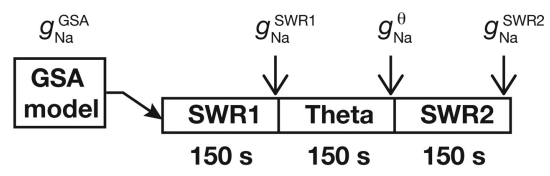

G

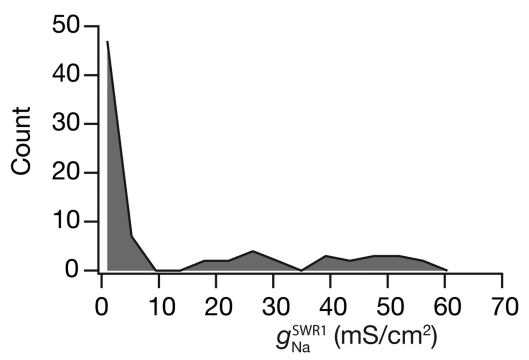

H

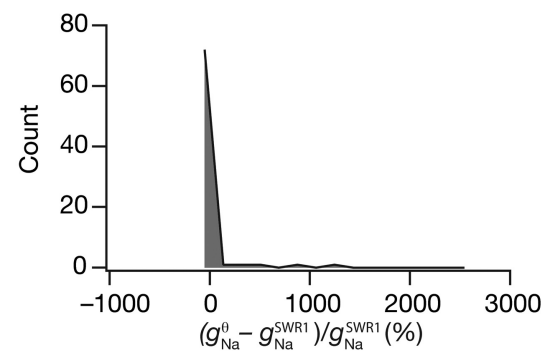

I

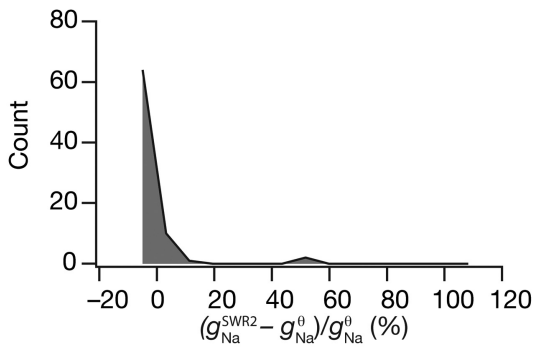

J

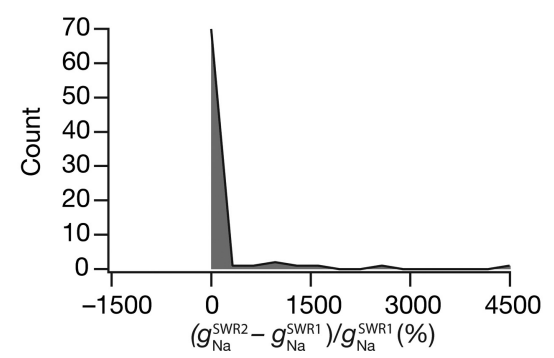

Figure 8. Across different model neurons, switch in afferent activity between $\theta$ oscillations and SWRs triggered variable changes in ionic conductances during cell-autonomous self-regulation of calcium homeostasis. $\boldsymbol{A}$, Schematic showing the temporal sequence of the experiment, along with notations for the temporal locations at which steady-state values of the sodium conductance $\left(g_{\mathrm{Na}}\right)$ were measured in the course of their calcium-dependent evolution. Note that this schematic represents a theta-SWR-theta temporal sequence in afferent activity, and the notations here hold for $\boldsymbol{B}-\boldsymbol{E}$. All histograms depict statistics across the 78 valid models obtained after GSA. B, Histogram of $g_{\mathrm{Na}}$ values at the steady state of the evolution with $\theta$-frequency oscillations as afferent inputs. Inset, Histogram of base values of $g_{\mathrm{Na}}$ obtained from GSA. $\boldsymbol{C}$, Histogram of percentage changes in $g_{\mathrm{Na}}$ measured at steady state of evolution with SWR inputs (after $\theta_{1}$-SWR), computed with reference to the steady state value after evolution with $\theta$-frequency oscillations $\left(\theta_{1}\right)$. $\boldsymbol{D}$, Histogram of percentage changes in $g_{\mathrm{Na}}$ measured at steady state of evolution with $\theta$-frequency oscillations (after $\left.\theta_{1}-\mathrm{SWR}-\theta_{2}\right)$, computed with reference to the steady state value after evolution with SWR inputs (after $\theta_{1}-S W R$ ). $\boldsymbol{E}$, Histogram of percentage changes in $g_{\mathrm{Na}}$ measured at steady state of evolution with $\theta$-frequency oscillations (after $\theta_{1}-\mathrm{SWR}-\theta_{2}$ ), computed with reference to $g_{\mathrm{Na}}$ measured at steady state of evolution after $\theta_{1}$. $\boldsymbol{F}-\boldsymbol{J}$, Same as $\boldsymbol{A}-\boldsymbol{E}$, but for a SWR-theta-SWR temporal sequence in afferent activity, with notations for conductance values shown in $\boldsymbol{F}$. 
A

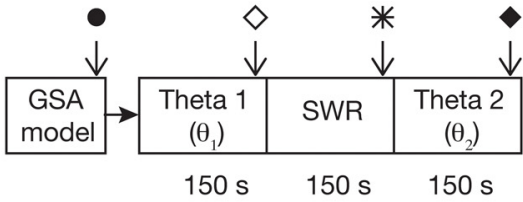

C

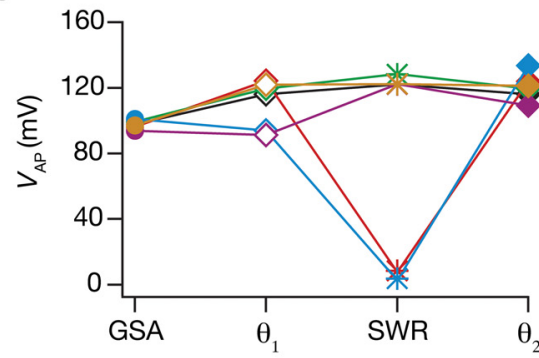

E

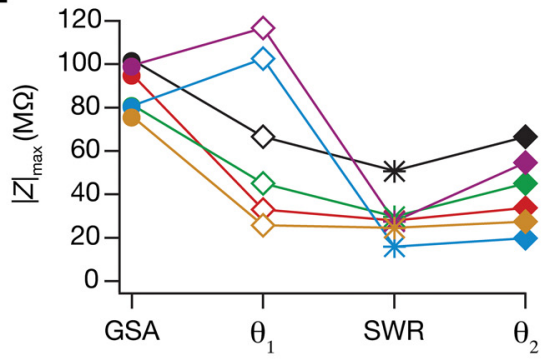

G

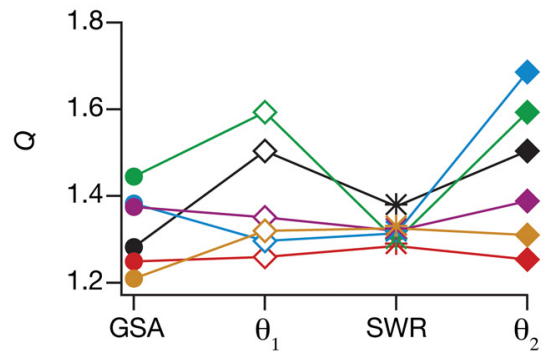

B

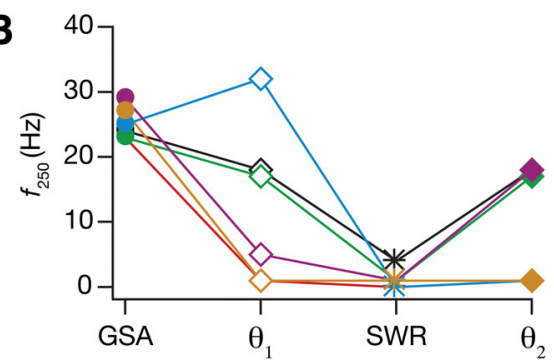

D

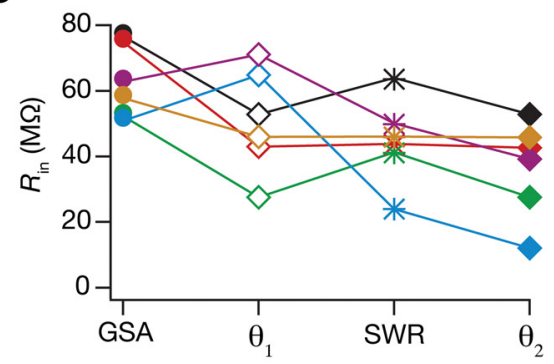

F

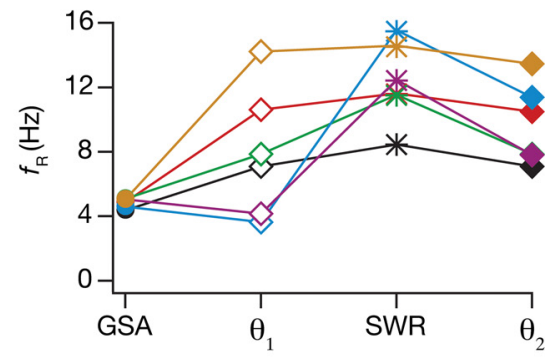

H

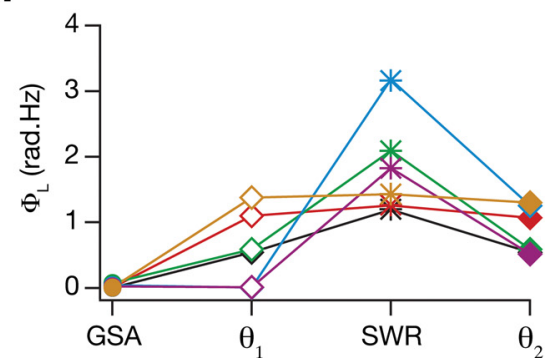

Figure 9. A Theta-SWR-theta switch in afferent activity introduced significant changes to neuronal intrinsic response properties during cell-autonomous self-regulation of calcium homeostasis. $\boldsymbol{A}$, Experimental design representing a theta-SWR-theta temporal sequence in afferent activity for assessing state-dependence of intrinsic response properties during cell-autonomous self-regulation of calcium homeostasis. The arrows represent time points at which intrinsic measurements were computed, and also associated with different symbols used in $\boldsymbol{B}-\boldsymbol{H}$. $\boldsymbol{B}-\boldsymbol{H}$, Intrinsic measurements $\left(f_{250}, \boldsymbol{B} ; V_{\mathrm{AP}}, \boldsymbol{C} ; \boldsymbol{R}_{\mathrm{in}}, \boldsymbol{D} ;|Z|_{\max }, \boldsymbol{E} ; f_{\mathrm{R}}, \boldsymbol{F} ; \boldsymbol{Q}, \boldsymbol{G} ; \Phi_{\mathrm{L}}, \boldsymbol{H}\right)$ for six example neurons (different colors) computed for the base valid model (GSA), and at different steady-state time points corresponding to different activity patterns $(\boldsymbol{A})$.

Together, our results suggest that neuronal conductances and intrinsic properties could undergo significant plasticity toward maintenance of calcium homeostasis in the face of behavioral-state dependent changes in afferent activity. Although a significant population of neurons exhibited robustness to an intervening switch in the type of afferent activity, there were neurons that manifested significantly distinct intrinsic properties upon restoration of the type of afferent activity after the intervening switch. These results suggest that neuronal conductances and intrinsic properties exhibited differential robustness to an intervening switch in the type of afferent activity, apart from demonstrating significant dissociations between functional/channel/firing-rate and calcium homeostasis.

\section{DISCUSSION}

The key conclusion of this study is that neuronal ionic conductances and intrinsic properties could undergo significant plasticity in the process of maintaining calcium homeostasis through a regime of behavioral state-dependent 
A

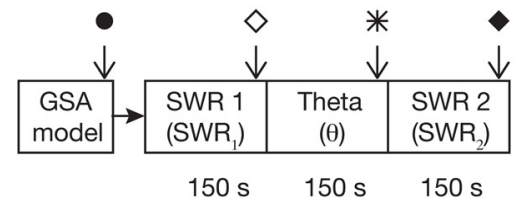

C

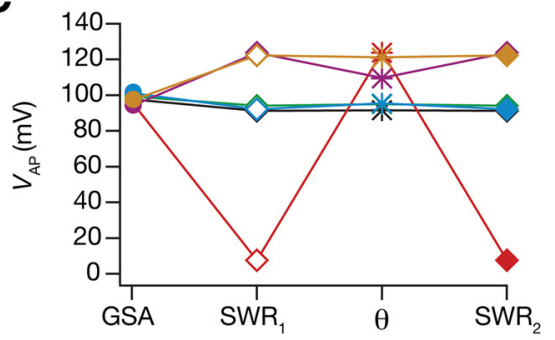

E

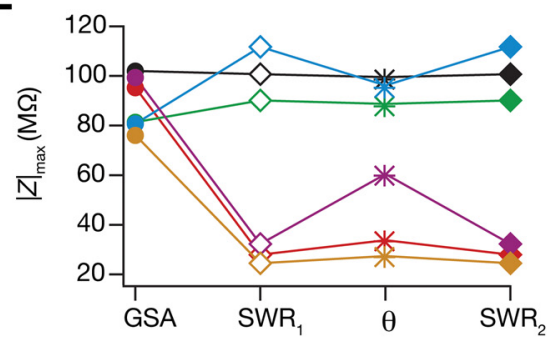

G

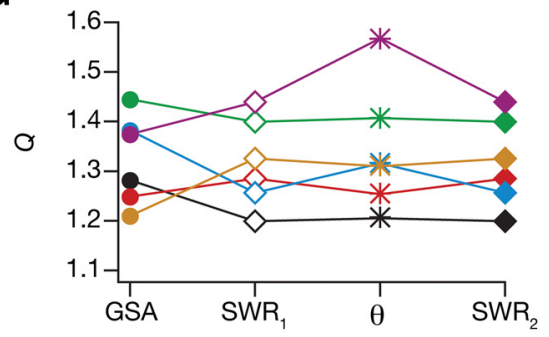

B

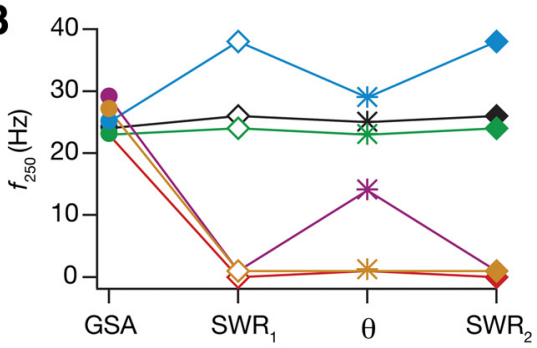

D

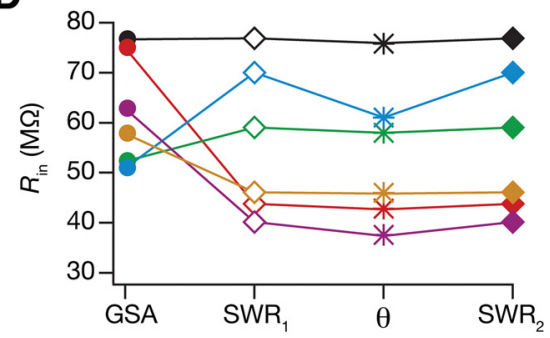

F

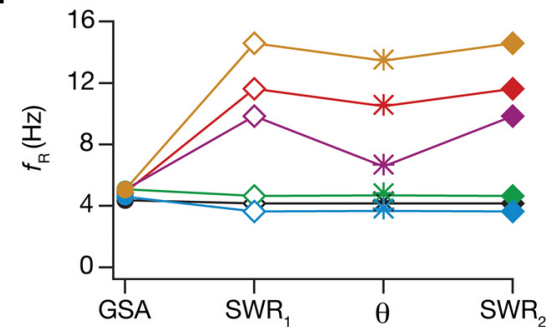

H

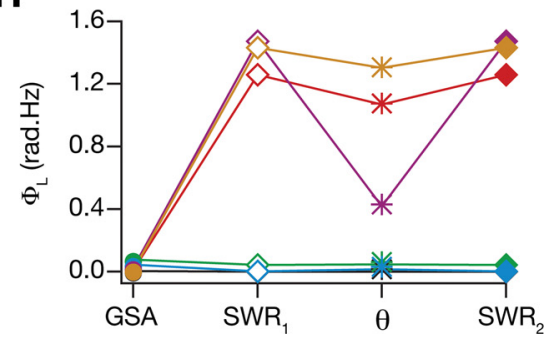

Figure 10. An SWR-theta-SWR switch in afferent activity introduced significant changes to neuronal intrinsic response properties during cell-autonomous self-regulation of calcium homeostasis. $\boldsymbol{A}$, Experimental design, representing a SWR-theta-SWR temporal sequence in afferent activity, for assessing state-dependence of intrinsic response properties during cell-autonomous self-regulation of calcium homeostasis. The arrows represent time points at which intrinsic measurements were computed, and also associated with different symbols used in $\boldsymbol{B}-\boldsymbol{H}$. $\boldsymbol{B}-\boldsymbol{H}$, Intrinsic measurements $\left(f_{250}, \boldsymbol{B} ; V_{\mathrm{AP}}, \boldsymbol{C} ; \boldsymbol{R}_{\mathrm{in}}, \boldsymbol{D} ;|Z|_{\max }, \boldsymbol{E} ; f_{\mathrm{R}}, \boldsymbol{F} ; \boldsymbol{Q}, \boldsymbol{G} ; \Phi_{\mathrm{L}}, \boldsymbol{H}\right)$ for six example neurons (different colors) computed for the base valid model (GSA), and at different steady-state time points corresponding to different activity patterns $(\boldsymbol{A})$.

changes in afferent activity. This form of intrinsic plasticity driven by calcium homeostasis was sensitive to the specific value of target calcium and the strength and frequency of afferent activity. We assessed the impact of behavioral state-dependence of afferent activity on calcium homeostasis by switching afferent activity pattern between theta-frequency oscillations (REM sleep/exploratory behavior) and SWR activity (non-REM sleep/nonexploratory behavior). Switches in activity patterns resulted in variable plasticity in ionic conductances and neuronal measurements, with the sign and strength of plasticity dependent on the specific type of activity pat- tern and on the temporal sequence of switch. Additionally, our analysis with temporal sequences of activity switch revealed the presence of two classes of neurons. One that showed significant plasticity in conductance values and in intrinsic properties when presented with identical activity patterns after an intervening period with a different activity pattern, and a second that restored its conductance values and intrinsic properties after the intervening period. The percentage of robust versus plastic neurons was variable in a manner that was critically dependent on the specific sequence of switch in activity. Finally, our results also reveal that the maintenance of calcium homeostasis 

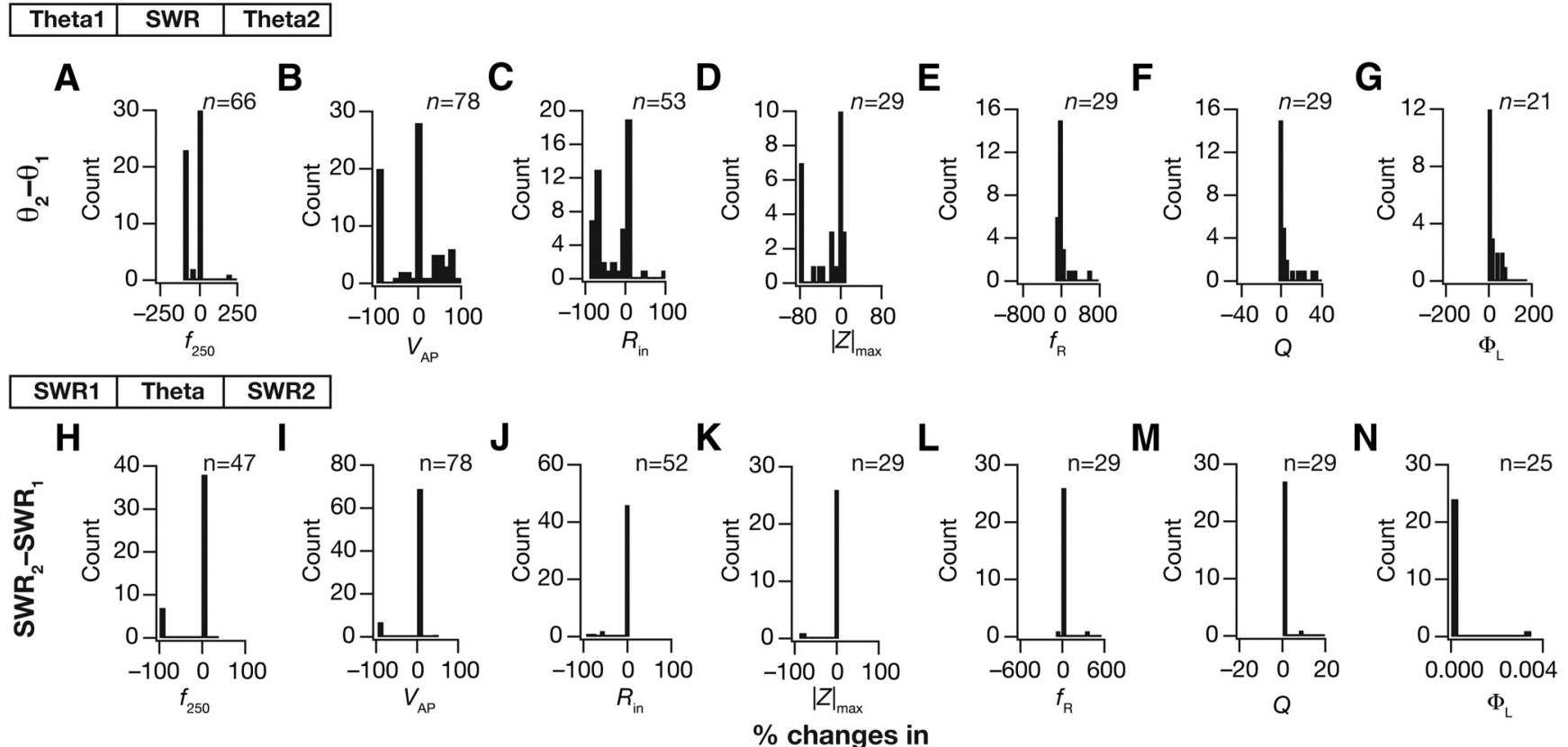

Figure 11. Across different model neurons, switch in afferent activity between $\theta$ oscillations and SWRs triggered variable changes in neuronal intrinsic response properties during cell-autonomous self-regulation of calcium homeostasis. $\boldsymbol{A}-\boldsymbol{G}, \theta_{1}-\mathbf{S W R}-\theta_{2}$ constitutes the temporal sequence of afferent activity, with notations shown in Figure $9 A$. Histogram of percentage changes in the seven intrinsic response properties $\left(f_{250}, \boldsymbol{A} ; V_{\mathrm{AP}}, \boldsymbol{B} ; R_{\mathrm{in}}, \boldsymbol{C} ;|Z|_{\max }, \boldsymbol{D} ; f_{\mathrm{R}}, \boldsymbol{E} ; \boldsymbol{Q}, \boldsymbol{F} ; \Phi_{\mathrm{L}}, \boldsymbol{G}\right)$ measured at steady state of evolution with $\theta$-frequency oscillations (after $\theta_{1}-\mathrm{SWR}-\theta_{2}$ ), computed with reference to the corresponding base value of the intrinsic property measured at steady state of evolution after $\theta_{1}$. Percentage changes in subthreshold measurements $\left(R_{\mathrm{in}},|Z|_{\max }, f_{\mathrm{R}}, Q, \Phi_{\mathrm{L}}\right)$ were computed only for those models that did not fire action potentials in response to the injected stimulus. In addition, models that showed very high percentage changes in $\Phi_{\mathrm{L}}$ were eliminated. The number of models $(n)$ used for each histogram is mentioned in the respective panel. $\boldsymbol{H}-\boldsymbol{N}$, Same as $\boldsymbol{A}-\boldsymbol{G}$, but for a $S W R_{1}$-theta-SWR $R_{2}$ temporal sequence of afferent activity, with notations shown in Figure $10 A$.

does not necessarily translate to the emergence of individual channelostasis or of functional homeostasis (across physiological measurements, including firing rate), thereby establishing critical dissociations between these forms of homeostasis. In what follows, we present certain physiological implications for our conclusions, along with detailed analyses on model assumptions and future directions with testable predictions.

\section{Behavioral state-dependent changes in neuronal intrinsic properties}

Afferent activity patterns in hippocampal pyramidal neurons exhibit well-established distinctions that reflect the behavioral state of the animal (Anderson et al., 2007). The literature on behavioral state-dependent changes in neuronal activity has largely focused on postulates that involve synaptic normalization and synaptic plasticity during activity switches (Tononi and Cirelli, 2006; Chauvette et al., 2012; Grosmark et al., 2012; Barnes and Wilson, 2014), or on how dendritic nonlinearities could differentially process different forms of activity patterns (Gasparini and Magee, 2006). Our results point to a novel form of behavioral state-dependent plasticity in neuronal intrinsic properties, emerging as a direct consequence of the requirement to maintain calcium homeostasis in the face of changes in afferent activity. In this context, it is important that future studies on behavioral-state dependence of neuronal physiology also consider the role of neuronal intrinsic properties and ionic conductances toward changes in overall firing rate (Tononi and Cirelli, 2006; Grosmark et al., 2012), without limiting the analysis to synaptic changes and neuromodulatory influences (LeMasson et al., 1993; Siegel et al., 1994; Turrigiano, 1999; Turrigiano and Nelson, 2000, 2004; Prinz et al., 2004; Triesch, 2007; Turrigiano, 2007; Marder, 2011; Honnuraiah and Narayanan, 2013; Marder et al., 2014; O'Leary et al., 2014). Additionally, although it is established that the propensity of different activity patterns is higher during specific behavioral states, a constant afferent pattern used in the model is physiologically infeasible under in vivo conditions. Future experiments should therefore explore the relationships between time constants for channel plasticity under in vivo conditions and the temporal extent of specific afferent activity patterns. Although in vitro experiments have shown plasticity in several ion channels to occur in a matter of minutes and have demonstrated that changes in ion channels and intrinsic properties can be concurrent with synaptic changes (Frick et al., 2004; Fan et al., 2005; Kim et al., 2007; Narayanan and Johnston, 2007; Lin et al., 2008; Losonczy et al., 2008; Narayanan and Johnston, 2008; Rosenkranz et al., 2009; Narayanan et al., 2010; Remy et al., 2010; Shah et al., 2010), the temporal aspects of activity-dependent plasticity in ion channels under in vivo conditions needs to be explored in detail, in a manner that accounts for channelostasis individually and collectively 
(Hanus and Schuman, 2013; Rathour and Narayanan, 2014; Anirudhan and Narayanan, 2015). Additionally, such experiments could test for variability in such statedependent intrinsic plasticity predicted by our model, apart from addressing the impact of such variability on neurophysiology and behavior.

As a specific instance, the existence of plasticity in intrinsic properties (in addition to synaptic plasticity) would expand the putative mechanisms that could be involved in memory consolidation, a postulated function for sleep rhythms (Siegel, 2001; Stickgold et al., 2002; Walker and Stickgold, 2004; Stickgold, 2005; Marshall and Born, 2007). As activity-dependent plasticity in neuronal intrinsic properties is well established (Zhang and Linden, 2003; Kim and Linden, 2007; Johnston and Narayanan, 2008; Shah et al., 2010; Narayanan and Johnston, 2012), the exploration of the postulate that memory consolidation is effectuated through intrinsic plasticity (in conjunction with synaptic changes) is a critical prediction that needs rigorous experimental evaluation. Given this postulate where the possibility of intrinsic changes exists, interpretation of observations from experiments that involve replay or disruption of specific activity pattern (Girardeau et al., 2009; Ego-Stengel and Wilson, 2010; Jadhav et al., 2012; Barnes and Wilson, 2014) should also account for changes in neuronal intrinsic properties that might have been brought about by the specific activity pattern or lack thereof.

\section{Would behavioral state-dependent intrinsic plasticity in a neuronal compartment be dependent on its somatodendritic location?}

Although the macroscopic activity patterns recorded in the hippocampus show theta-SWR switches during different behavioral states, it is evident that there are subtle, yet significant, differences in afferent activity at different somatodendritic locations along a hippocampal pyramidal neuron (Colgin et al., 2009; Colgin and Moser, 2010; Bieri et al., 2014; Schomburg et al., 2014). Additionally, there are well-established differences in localization of different ion channels (Johnston et al., 1996; Magee, 2000; Migliore and Shepherd, 2002; Johnston and Narayanan, 2008; Spruston, 2008; Narayanan and Johnston, 2012), in the locus of plasticity in these channels (Frick et al., 2004; Narayanan and Johnston, 2007; Losonczy et al., 2008; Narayanan et al., 2010; Shah et al., 2010), and in calcium source localization and calcium propagation (Magee and Johnston, 1995; Augustine et al., 2003; Hertle and Yeckel, 2007; Ross, 2012) across the somatodendritic arbor. Consistent with this, and given our results with a single-compartmental model (necessitated by the tremendous computational complexity of calciumdependent evolution), we postulate that the behavioralstate dependent intrinsic plasticity reported here would be dependent on the somatodendritic location of the neuronal compartment.

Testing this postulate would require development of specific experimental techniques and computational models to assess the impact of the self-regulating evolution of calcium homeostasis on changes in localization profiles of ion channels across the somatodendritic arbor. Experimental procedures would require direct measurement of somatodendritic channel properties under in vivo conditions, during different stages of sleep or behavior, with location-dependent afferent activity monitored in parallel (Agarwal et al., 2014; Schomburg et al., 2014). These experiments would provide direct answers to questions on whether dendritic channel localization profiles change as a function of activity switch (during specific stages of sleep or behavior), and if neurons implement an efficient form of neural coding that accounts the statistics of their afferent activity (Stemmler and Koch, 1999; Simoncelli and Olshausen, 2001; Simoncelli, 2003; Narayanan and Johnston, 2012).

Computational models, on the other hand, would have to explicitly account for somatodendritic differences in ion channel profiles, physiological measurements and calcium source localization (Berridge, 2006; Vacher et al., 2008; Kotaleski and Blackwell, 2010; Nusser, 2012; Ashhad and Narayanan, 2013; Hanus and Schuman, 2013; Rathour and Narayanan, 2014), apart from ensuring that spatial compartmentalization of the neuronal model is based on the calcium space constant rather than the electrical space constant (Koch and Zador, 1993; Zador and Koch, 1994; Ashhad and Narayanan, 2013). Second, these models would have to address the question on whether calcium homeostasis is maintained globally or locally, and ask if localization profiles of different channels were emergent properties consequent to the cellautonomous calcium homeostasis process (Siegel et al., 1994; Rabinowitch and Segev, 2006, 2008). Third, consistent with the existence of several enzymes that act as calcium sensors (Liu et al., 1998), and the existence of several activity-dependent transcription factors (Dolmetsch, 2003), future models should extend beyond the single transcription factor-based analysis used in our model (see below). Finally, in our study, we have not accounted for neuromodulatory influences, and have resorted to a simplistic classification of afferent activity as theta versus SWR. Future experimental and computational studies on state-dependent calcium homeostasis should also account for differences in neuromodulatory activity during REM versus exploratory behavior and non-REM versus non-exploratory behavior (Vertes, 1984; Steriade, 2004; McCarley, 2007; Lee and Dan, 2012), and the impact of each of such differential neuromodulatory activity on ion channels and their plasticity (Fisher and Johnston, 1990; Hoffman and Johnston, 1999; Cantrell and Catterall, 2001; Marder and Thirumalai, 2002; Perez-Reyes, 2003; Biel et al., 2009; Marder, 2012; Marder et al., 2014).

What is the impact of such location-dependent plasticity in somato-dendritic channel properties on neuronal physiology and behaviorally relevant neural computation? First, such plasticity would alter the following physiological characteristics of these neuronal structures, each of which is known to exhibit location-dependence in a manner dependent on specific ion channel combinations: spectral selectivity (Narayanan and Johnston, 2007; Hu et al., 2009; Das and Narayanan, 2014), coincidence detection (Johnston et al., 2003; London and Häusser, 2005; 
Sjöström et al., 2008; Das and Narayanan, 2015), impedance phase (Narayanan and Johnston, 2008; Vaidya and Johnston, 2013), and supralinear summation (Losonczy and Magee, 2006; Losonczy et al., 2008; Sjöström et al., 2008; Spruston, 2008; Takahashi and Magee, 2009). Importantly, such state-dependent plasticity in channel conductances would not just reflect as changes in intrinsic neuronal physiology, but also express as changes in the amplitude and phase of local field potentials (LFP) and associated neuronal spike phases (Buzsáki et al., 2012; Schomburg et al., 2012; Einevoll et al., 2013; Reimann et al., 2013; Sinha and Narayanan, 2015). Future studies should test if such intrinsically-driven changes in LFP and spike phase could potentially form a cellular substrate for REM-shifting neurons (Mizuseki et al., 2011), a scenario where the phase shift is a consequence of intrinsic plasticity that occurred during an intervening switch to nonREM activity (Figs. 7-9, 11). Finally, extrapolating from recent studies that have demonstrated the importance of dendritic nonlinearities to place cell formation (Bittner et al., 2015; Sheffield and Dombeck, 2015), changes in dendritic sodium/calcium/potassium/HCN channels would alter the propensity for generating dendritic plateau potentials (Golding et al., 1999; Gasparini and Magee, 2002; Gasparini et al., 2004; Losonczy and Magee, 2006; Tsay et al., 2007; Losonczy et al., 2008), potentially resulting in changes in the place cell properties of the associated hippocampal neurons (Bittner et al., 2015).

\section{Implications for the assumption on a single transcription factor}

In our model, we have assumed that the channel conductances are regulated by a single transcription factor (O'Leary et al., 2014), an assumption that significantly oversimplifies the complexities of neuronal transcription, where multiple transcription factors coexist (Bading et al., 1993; Dolmetsch, 2003; Lein et al., 2007; Alberini, 2009). This assumption implies that proportions of changes in channel conductances are correlated (Fig. $3 A$ ), resulting in correlated channel expression profiles (O'Leary et al., 2014). Although this assumption was motivated by correlated expression profiles of ion channels in certain neuronal subtypes (Toledo-Rodriguez et al., 2004; Schulz et al., 2006, 2007; Tobin et al., 2009; Amendola et al., 2012), detailed quantitative analysis of channel conductances and mRNA expression has not been performed in single hippocampal neurons. In the absence of such experimental data, not just at the cell body, but across the somatodendritic arbor (Hanus and Schuman, 2013; Rathour and Narayanan, 2014), model-based extrapolations about correlations in expression profiles of hippocampal channels or mRNAs would be incorrect, because the model outcome is just a direct consequence of the assumption involving a single transcription factor. Therefore, we restrict our inferences from this simple model to: (1) variable state-dependent plasticity of ionic conductances and intrinsic properties toward cell-autonomous maintenance of calcium homeostasis and (2) significant dissociation between different forms of homeostasis (see below), which also form testable predictions from our analysis. The question on whether the expression profiles of different channels/mRNAs are correlated or lack significant correlation in the presence of multiple transcription factors needs to be rigorously addressed both from experimental as well as theoretical standpoints.

Incorporation of multiple transcription factors into a model for cell-autonomous calcium homeostasis has been reported to result in unbounded production of $\mathrm{mR}$ NAs and channels ("windup"), leading to eventual loss of regulatory control (O'Leary et al., 2014). Although this constitutes a significant impediment to the incorporation of multiple transcription factors into models, this analysis was performed in a manner where the different transcription factors were independent of each other (O'Leary et al., 2014). Future theoretical studies should explore the possibility of avoiding such windup by coupling the multiple calcium sensors and multiple transcription factors through established signaling motifs, including negative feedback mechanisms (Thattai and van Oudenaarden, 2001; Losick and Desplan, 2008; Yu et al., 2008; Kotaleski and Blackwell, 2010; Cheong et al., 2011). Experimental studies should explore the relationships between the different transcription factors, mRNAs and channel conductances across the somatodendritic arbor of single hippocampal neurons (Dolmetsch, 2003; Hanus and Schuman, 2013).

\section{Dissociations between different forms of homeostasis}

It is clear from our analyses here, and from several others in the literature, that there are significant dissociations between different forms of homeostasis. First, homeostasis in functional properties, including synaptic plasticity profiles (Anirudhan and Narayanan, 2015), could emerge with disparate conductance values for the constituent ion channels and synaptic conductances (Golowasch and Marder, 1992; Golowasch et al., 2002; MacLean et al., 2005; Schulz et al., 2006, 2007; Taylor et al., 2009; Rathour and Narayanan, 2012a, 2014), suggesting that homeostatic maintenance of single channels at specific conductance values is not essential for maintaining functional or plasticity profile homeostasis. Second, for maintenance of calcium homeostasis across neurons in a network (O'Leary et al., 2013), or in a neuron that receives state-dependent switch in afferent activity (Figs. 3-11), it is not essential that functional homeostasis across different measurements is maintained. Specifically, despite maintenance of calcium homeostasis across models receiving identical temporal evolution of afferent activity, we noted that the conductance values (Figs. 3,8 ) and physiological measurements (Figs. 3-6, 9-11) were significantly variable across these models, with some models manifesting measurements beyond what is expected from CA1 pyramidal neurons. Additionally, a significant proportion of neurons did not restore their intrinsic properties despite restoration of specific type of activity after an intervening switch to a different type of activity (Figs. 9-11). Finally, although calcium homeostasis was achieved across all neuronal models, there was significant variability (across models) in the firing rate and in pattern 
of firing in response to the same afferent activity (Figs. 3,7; O'Leary et al., 2013, 2014). Together, these results clearly establish that maintenance of calcium homeostasis neither translates to nor follows from any of channel/ functional/firing-rate forms of homeostasis, outlining critical dissociations between these forms of homeostasis.

Future experiments should therefore explore the specific form of homeostasis maintained by individual neurons and their dendritic arbor when subjected to behavioral state-dependent afferent activity during different stages of sleep and behavior. Do channel properties/ localization and intrinsic functional properties change in the process of maintaining calcium homeostasis? Or, do neurons implement a mechanism where all forms of homeostasis-including that in spatially distributed channel properties, intrinsic response properties, plasticity profiles, and calcium levels-are concurrently maintained across all somatodendritic locations of the neuron, with firing rate homeostasis emerging as an overall consequence? Should a homeostatic mechanism account not just for the average calcium level in a neuron, but also make provisions for the homeostasis in input-output profiles, intrinsic response properties and synaptic/intrinsic plasticity profiles of the neuron through synergistic interactions between synaptic and intrinsic neuronal properties (LeMasson et al., 1993; Liu et al., 1998; Triesch, 2007; Turrigiano, 2011; Honnuraiah and Narayanan, 2013; O'Leary et al., 2014; Anirudhan and Narayanan, 2015)? Finally, whereas homeostasis covers only one aspect of neuronal function, the other core function (especially of hippocampal neurons), is encoding of new information. Juxtaposed against questions on various forms of homeostasis is the fundamental issue of how neurons change their properties toward encoding new information, without jeopardizing any or some forms of homeostasis. Therefore, further exploration into behavioral statedependent evolution of homeostasis should account for encoding as a critical aspect of neuronal function that depends on changes in intrinsic and/or synaptic properties (Narayanan and Johnston, 2012), apart from exploring the relationships between different forms of homeostasis.

\section{REFERENCES}

Achard P, De Schutter E (2006) Complex parameter landscape for a complex neuron model. PLoS Comput Biol 2:e94. CrossRef Medline

Agarwal G, Stevenson IH, Berényi A, Mizuseki K, Buzsaki G, Sommer FT (2014) Spatially distributed local fields in the hippocampus encode rat position. Science 344:626-630. CrossRef Medline

Alberini CM (2009) Transcription factors in long-term memory and synaptic plasticity. Physiol Rev 89:121-145. CrossRef Medline

Alberts B, Johnson A, Lewis J, Raff M, Roberts K, Walter P (2007) Molecular biology of the cell, Ed 5. New York: Garland Science.

Allbritton NL, Meyer T, Stryer $L$ (1992) Range of messenger action of calcium ion and inositol 1,4,5-trisphosphate. Science 258:18121815. Medline

Amendola J, Woodhouse A, Martin-Eauclaire MF, Goaillard JM (2012) $\mathrm{Ca}(2)(+) / c A M P-$ sensitive covariation of $\mathrm{I}(\mathrm{A})$ and $\mathrm{I}(\mathrm{H})$ voltage dependences tunes rebound firing in dopaminergic neurons. $J$ Neurosci 32:2166-2181. CrossRef Medline

Anderson P, Morris R, Amaral D, Bliss TV, O'Keefe J (2007) The hippocampus book. New York: Oxford UP.
Anirudhan A, Narayanan R (2015) Analogous synaptic plasticity profiles emerge from disparate channel combinations. J Neurosci 35:4691-4705. CrossRef Medline

Ashhad S, Narayanan R (2013) Quantitative interactions between the A-type $\mathrm{K}+$ current and inositol trisphosphate receptors regulate intraneuronal $\mathrm{Ca} 2+$ waves and synaptic plasticity. J Physiol 591: 1645-1669. CrossRef Medline

Augustine GJ, Santamaria F, Tanaka K (2003) Local calcium signaling in neurons. Neuron 40:331-346. Medline

Bading H, Ginty DD, Greenberg ME (1993) Regulation of gene expression in hippocampal neurons by distinct calcium signaling pathways. Science 260:181-186. Medline

Barnes DC, Wilson DA (2014) Slow-wave sleep-imposed replay modulates both strength and precision of memory. J Neurosci 34:5134-5142. CrossRef Medline

Berridge MJ (2006) Calcium microdomains: organization and function. Cell calcium 40:405-412. CrossRef Medline

Bhalla US, Bower JM (1993) Exploring parameter space in detailed single neuron models: simulations of the mitral and granule cells of the olfactory bulb. J Neurophysiol 69:1948-1965. Medline

Biel M, Wahl-Schott C, Michalakis S, Zong X (2009) Hyperpolarization-activated cation channels: from genes to function. Physiol Rev 89:847-885. CrossRef Medline

Bieri KW, Bobbitt KN, Colgin LL (2014) Slow and fast $\gamma$ rhythms coordinate different spatial coding modes in hippocampal place cells. Neuron 82:670-681. CrossRef Medline

Bittner KC, Grienberger C, Vaidya SP, Milstein AD, Macklin JJ, Suh J, Tonegawa S, Magee JC (2015) Conjunctive input processing drives feature selectivity in hippocampal CA1 neurons. Nature Neuroscience 18:1133-1142.

Buzsáki G (1986) Hippocampal sharp waves: their origin and significance. Brain Res 398:242-252. CrossRef

Buzsáki G (1989) Two-stage model of memory trace formation: a role for "noisy" brain states. Neuroscience 31:551-570. CrossRef

Buzsáki G (2002) Theta oscillations in the hippocampus. Neuron 33:325-340. CrossRef

Buzsáki G (2006) Rhythms of the brain. New York: Oxford UP.

Buzsáki G, Leung LW, Vanderwolf CH (1983) Cellular bases of hippocampal EEG in the behaving rat. Brain research 287:139171. Medline

Buzsáki G, Horvath Z, Urioste R, Hetke J, Wise K (1992) Highfrequency network oscillation in the hippocampus. Science 256: 1025-1027. Medline

Buzsáki G, Anastassiou CA, Koch C (2012) The origin of extracellular fields and currents - EEG, ECoG, LFP and spikes. Nat Rev Neurosci 13:407-420. CrossRef Medline

Canavier CC (1999) Sodium dynamics underlying burst firing and putative mechanisms for the regulation of the firing pattern in midbrain dopamine neurons: a computational approach. J Comput Neurosci 6:49-69. Medline

Cantrell AR, Catterall WA (2001) Neuromodulation of $\mathrm{Na}+$ channels: an unexpected form of cellular plasticity. Nat Rev Neurosci 2:397407. CrossRef Medline

Carnevale NT, Hines ML (2006) The Neuron Book. Cambridge, UK: Cambridge UP.

Chauvette S, Seigneur J, Timofeev I (2012) Sleep oscillations in the thalamocortical system induce long-term neuronal plasticity. Neuron 75:1105-1113. CrossRef Medline

Cheong R, Rhee A, Wang CJ, Nemenman I, Levchenko A (2011) Information transduction capacity of noisy biochemical signaling networks. Science 334:354-358. CrossRef Medline

Colgin LL, Moser El (2010) Gamma oscillations in the hippocampus. Physiology 25:319-329. CrossRef Medline

Colgin LL, Denninger T, Fyhn M, Hafting T, Bonnevie T, Jensen O, Moser MB, Moser El (2009) Frequency of gamma oscillations routes flow of information in the hippocampus. Nature 462:353357. CrossRef Medline

Csicsvari J, Hirase H, Czurko A, Mamiya A, Buzsáki G (1999) Oscillatory coupling of hippocampal pyramidal cells and interneurons in the behaving Rat. J Neurosci 19:274-287. Medline 
Das A, Narayanan R (2014) Active dendrites regulate spectral selectivity in location-dependent spike initiation dynamics of hippocampal model neurons. J Neurosci 34:1195-1211. CrossRef Medline

Das A, Narayanan R (2015) Active dendrites mediate stratified gamma-range coincidence detection in hippocampal model neurons. J Physiol. 593:3549-3576.

Dingledine R, Borges K, Bowie D, Traynelis SF (1999) The glutamate receptor ion channels. Pharmacol Rev 51:7-61. Medline

Dolmetsch R (2003) Excitation-transcription coupling: signaling by ion channels to the nucleus. Sci STKE 2003:PE4. CrossRef Medline

Ego-Stengel V, Wilson MA (2010) Disruption of ripple-associated hippocampal activity during rest impairs spatial learning in the rat. Hippocampus 20:1-10. CrossRef Medline

Einevoll GT, Kayser C, Logothetis NK, Panzeri S (2013) Modelling and analysis of local field potentials for studying the function of cortical circuits. Nat Rev Neurosci 14:770-785. CrossRef Medline

English DF, Peyrache A, Stark E, Roux L, Vallentin D, Long MA, Buzsaki G (2014) Excitation and inhibition compete to control spiking during hippocampal ripples: intracellular study in behaving mice. J Neurosci 34:16509-16517. CrossRef

Fan Y, Fricker D, Brager DH, Chen X, Lu HC, Chitwood RA, Johnston D (2005) Activity-dependent decrease of excitability in rat hippocampal neurons through increases in I(h). Nat Neurosci 8:15421551. CrossRef Medline

Fink CC, Slepchenko B, Moraru, II, Watras J, Schaff JC, Loew LM (2000) An image-based model of calcium waves in differentiated neuroblastoma cells. Biophys J 79:163-183. CrossRef Medline

Fisher R, Johnston D (1990) Differential modulation of single voltagegated calcium channels by cholinergic and adrenergic agonists in adult hippocampal neurons. J Neurophysiol 64:1291-1302. Medline

Foster WR, Ungar LH, Schwaber JS (1993) Significance of conductances in Hodgkin-Huxley models. J Neurophysiol 70:2502-2518. Medline

Frick A, Magee J, Johnston D (2004) LTP is accompanied by an enhanced local excitability of pyramidal neuron dendrites. Nat Neurosci 7:126-135. CrossRef Medline

Gasparini S, Magee JC (2002) Phosphorylation-dependent differences in the activation properties of distal and proximal dendritic $\mathrm{Na}+$ channels in rat CA1 hippocampal neurons. J Physiol 541: 665-672. Medline

Gasparini S, Magee JC (2006) State-dependent dendritic computation in hippocampal CA1 pyramidal neurons. J Neurosci 26:20882100. CrossRef Medline

Gasparini S, Migliore M, Magee JC (2004) On the initiation and propagation of dendritic spikes in CA1 pyramidal neurons. J Neurosci 24:11046-11056. CrossRef Medline

Girardeau G, Benchenane K, Wiener SI, Buzsáki G, Zugaro MB (2009) Selective suppression of hippocampal ripples impairs spatial memory. Nat Neurosci 12:1222-1223. CrossRef Medline

Golding NL, Jung HY, Mickus T, Spruston N (1999) Dendritic calcium spike initiation and repolarization are controlled by distinct potassium channel subtypes in CA1 pyramidal neurons. J Neurosci 19:8789-8798. Medline

Goldman DE (1943) Potential, impedance, and rectification in membranes. J Gen Physiol 27:37-60. Medline

Goldman MS, Golowasch J, Marder E, Abbott LF (2001) Global structure, robustness, and modulation of neuronal models. J Neurosci 21:5229-5238. Medline

Golowasch J, Marder E (1992) lonic currents of the lateral pyloric neuron of the stomatogastric ganglion of the crab. J Neurophysiol 67:318-331. Medline

Golowasch J, Goldman MS, Abbott LF, Marder E (2002) Failure of averaging in the construction of a conductance-based neuron model. J Neurophysiol 87:1129-1131. Medline

Grosmark AD, Mizuseki K, Pastalkova E, Diba K, Buzsáki G (2012) REM sleep reorganizes hippocampal excitability. Neuron 75:10011007. CrossRef Medline
Hanus C, Schuman EM (2013) Proteostasis in complex dendrites. Nat Rev Neurosci 14:638-648. CrossRef Medline

Harvey CD, Collman F, Dombeck DA, Tank DW (2009) Intracellular dynamics of hippocampal place cells during virtual navigation. Nature 461:941-946. CrossRef Medline

Herrington J, Park YB, Babcock DF, Hille B (1996) Dominant role of mitochondria in clearance of large $\mathrm{Ca} 2+$ loads from rat adrenal chromaffin cells. Neuron 16:219-228. Medline

Hertle DN, Yeckel MF (2007) Distribution of inositol-1,4,5trisphosphate receptor isotypes and ryanodine receptor isotypes during maturation of the rat hippocampus. Neuroscience 150:625638. CrossRef Medline

Hobbs KH, Hooper SL (2008) Using complicated, wide dynamic range driving to develop models of single neurons in single recording sessions. J Neurophysiol 99:1871-1883. CrossRef Medline

Hodgkin AL, Katz B (1949) The effect of sodium ions on the electrical activity of giant axon of the squid. J Physiol 108:37-77. Medline

Hoffman DA, Johnston D (1999) Neuromodulation of dendritic action potentials. J Neurophysiol 81:408-411. Medline

Hoffman DA, Magee JC, Colbert CM, Johnston D (1997) K+ channel regulation of signal propagation in dendrites of hippocampal pyramidal neurons. Nature 387:869-875. CrossRef Medline

Honnuraiah S, Narayanan R (2013) A calcium-dependent plasticity rule for $\mathrm{HCN}$ channels maintains activity homeostasis and stable synaptic learning. PloS One 8:e55590. CrossRef Medline

Hu H, Vervaeke K, Graham LJ, Storm JF (2009) Complementary theta resonance filtering by two spatially segregated mechanisms in CA1 hippocampal pyramidal neurons. J Neurosci 29:1447214483. CrossRef Medline

Jadhav SP, Kemere C, German PW, Frank LM (2012) Awake hippocampal sharp-wave ripples support spatial memory. Science 336:1454-1458. CrossRef Medline

Jahr CE, Stevens CF (1990) Voltage dependence of NMDA-activated macroscopic conductances predicted by single-channel kinetics. J Neurosci 10:3178-3182. Medline

Johnston D, Narayanan R (2008) Active dendrites: colorful wings of the mysterious butterflies. Trends Neurosci 31:309-316. CrossRef Medline

Johnston D, Magee JC, Colbert CM, Cristie BR (1996) Active properties of neuronal dendrites. Annu Rev Neurosci 19:165-186. CrossRef Medline

Johnston D, Christie BR, Frick A, Gray R, Hoffman DA, Schexnayder LK, Watanabe S, Yuan LL (2003) Active dendrites, potassium channels and synaptic plasticity. Philos Trans R Soc London B Biol Sci 358:667-674. CrossRef Medline

Kim J, Jung SC, Clemens AM, Petralia RS, Hoffman DA (2007) Regulation of dendritic excitability by activity-dependent trafficking of the A-type $\mathrm{K}+$ channel subunit Kv4.2 in hippocampal neurons. Neuron 54:933-947. CrossRef Medline

Kim SJ, Linden DJ (2007) Ubiquitous plasticity and memory storage. Neuron 56:582-592. CrossRef Medline

Klingauf J, Neher E (1997) Modeling buffered Ca2 + diffusion near the membrane: implications for secretion in neuroendocrine cells. Biophys J 72:674-690. Medline

Koch C, Zador A (1993) The function of dendritic spines: devices subserving biochemical rather than electrical compartmentalization. J Neurosci 13:413-422. Medline

Kotaleski JH, Blackwell KT (2010) Modelling the molecular mechanisms of synaptic plasticity using systems biology approaches. Nat Rev Neurosci 11:239-251. CrossRef Medline

Lee SH, Dan Y (2012) Neuromodulation of brain states. Neuron 76:209-222. CrossRef Medline

Lein ES, et al. (2007) Genome-wide atlas of gene expression in the adult mouse brain. Nature 445:168-176. CrossRef Medline

LeMasson G, Marder E, Abbott LF (1993) Activity-dependent regulation of conductances in model neurons. Science 259:1915-1917. Medline

Lin MT, Luján R, Watanabe M, Adelman JP, Maylie J (2008) SK2 channel plasticity contributes to LTP at Schaffer collateral-CA1 synapses. Nat Neurosci 11:170-177. CrossRef Medline 
Liu Z, Golowasch J, Marder E, Abbott LF (1998) A model neuron with activity-dependent conductances regulated by multiple calcium sensors. J Neurosci 18:2309-2320. Medline

London M, Häusser M (2005) Dendritic computation. Annu Rev Neurosci 28:503-532. CrossRef Medline

Losick R, Desplan C (2008) Stochasticity and cell fate. Science 320:65-68. CrossRef Medline

Losonczy A, Magee JC (2006) Integrative properties of radial oblique dendrites in hippocampal CA1 pyramidal neurons. Neuron 50:291307. CrossRef Medline

Losonczy A, Makara JK, Magee JC (2008) Compartmentalized dendritic plasticity and input feature storage in neurons. Nature 452 : 436-441. CrossRef Medline

Louie K, Wilson MA (2001) Temporally structured replay of awake hippocampal ensemble activity during rapid eye movement sleep. Neuron 29:145-156. Medline

MacLean JN, Zhang Y, Goeritz ML, Casey R, Oliva R, Guckenheimer J, Harris-Warrick RM (2005) Activity-independent coregulation of IA and Ih in rhythmically active neurons. J Neurophysiol 94:36013617. CrossRef Medline

Magee JC (1998) Dendritic hyperpolarization-activated currents modify the integrative properties of hippocampal CA1 pyramidal neurons. J Neurosci 18:7613-7624. Medline

Magee JC (2000) Dendritic integration of excitatory synaptic input. Nat Rev Neurosci 1:181-190. CrossRef Medline

Magee JC, Johnston D (1995) Characterization of single voltagegated $\mathrm{Na}+$ and $\mathrm{Ca} 2+$ channels in apical dendrites of rat CA1 pyramidal neurons. J Physiol 487:67-90. CrossRef

Marder E (2011) Variability, compensation, and modulation in neurons and circuits. Proc Natl Acad Sci U S A 108:15542-15548. CrossRef Medline

Marder E (2012) Neuromodulation of neuronal circuits: back to the future. Neuron 76:1-11. CrossRef Medline

Marder E, Thirumalai V (2002) Cellular, synaptic and network effects of neuromodulation. Neural Netw 15:479-493. Medline

Marder E, O'Leary T, Shruti S (2014) Neuromodulation of circuits with variable parameters: single neurons and small circuits reveal principles of state-dependent and robust neuromodulation. Annu Rev Neurosci 37:329-346. CrossRef Medline

Marshall L, Born J (2007) The contribution of sleep to hippocampusdependent memory consolidation. Trends Cogn Sci 11:442-450. CrossRef Medline

Mayer ML, Westbrook GL (1987) Permeation and block of N-methyld-aspartic acid receptor channels by divalent cations in mouse cultured central neurones. J Physiol 394:501-527. Medline

McCarley RW (2007) Neurobiology of REM and NREM sleep. Sleep Med 8:302-330. CrossRef Medline

Migliore M, Shepherd GM (2002) Emerging rules for the distributions of active dendritic conductances. Nat Rev Neurosci 3:362-370. CrossRef Medline

Migliore M, Hoffman DA, Magee JC, Johnston D (1999) Role of an A-type $\mathrm{K}+$ conductance in the back-propagation of action potentials in the dendrites of hippocampal pyramidal neurons. J Comput Neurosci 7:5-15. Medline

Migliore M, Cook EP, Jaffe DB, Turner DA, Johnston D (1995) Computer simulations of morphologically reconstructed CA3 hippocampal neurons. J Neurophysiol 73:1157-1168. Medline

Migliore M, Cannia C, Lytton WW, Markram H, Hines ML (2006) Parallel network simulations with NEURON. J Comput Neurosci 21:119-129. CrossRef Medline

Mizuseki K, Diba K, Pastalkova E, Buzsaki G (2011) Hippocampal CA1 pyramidal cells form functionally distinct sublayers. Nat Neurosci 14:1174-1181. CrossRef Medline[Mismatch]

Moczydlowski E, Latorre R (1983) Gating kinetics of Ca2+-activated $\mathrm{K}+$ channels from rat muscle incorporated into planar lipid bilayers. Evidence for two voltage-dependent $\mathrm{Ca} 2+$ binding reactions. J Gen Physiol 82:511-542. Medline

Montgomery SM, Sirota A, Buzsáki G (2008) Theta and gamma coordination of hippocampal networks during waking and rapid eye movement sleep. J Neurosci 28:6731-6741. CrossRef Medline
Narayanan R, Johnston D (2007) Long-term potentiation in rat hippocampal neurons is accompanied by spatially widespread changes in intrinsic oscillatory dynamics and excitability. Neuron 56:1061-1075. CrossRef Medline

Narayanan R, Johnston D (2008) The h channel mediates location dependence and plasticity of intrinsic phase response in rat hippocampal neurons. J Neurosci 28:5846-5860. CrossRef Medline

Narayanan R, Johnston D (2010) The h current is a candidate mechanism for regulating the sliding modification threshold in a BCMlike synaptic learning rule. J Neurophysiol 104:1020-1033. CrossRef Medline

Narayanan R, Johnston D (2012) Functional maps within a single neuron. J Neurophysiol 108:2343-2351. CrossRef Medline

Narayanan R, Dougherty KJ, Johnston D (2010) Calcium store depletion induces persistent perisomatic increases in the functional density of $h$ channels in hippocampal pyramidal neurons. Neuron 68:921-935. CrossRef Medline

Nusser Z (2012) Differential subcellular distribution of ion channels and the diversity of neuronal function. Curr Opin Neurobiol 22: 366-371. CrossRef Medline

O'Leary T, Williams AH, Caplan JS, Marder E (2013) Correlations in ion channel expression emerge from homeostatic tuning rules. Proc Natl Acad Sci U S A 110:E2645-2654.

O'Leary T, Williams AH, Franci A, Marder E (2014) Cell types, network homeostasis, and pathological compensation from a biologically plausible ion channel expression model. Neuron 82:809-821.

Perez-Reyes E (2003) Molecular physiology of low-voltage-activated t-type calcium channels. Physiol Rev 83:117-161. CrossRef Medline

Poirazi P, Brannon T, Mel BW (2003) Pyramidal neuron as two-layer neural network. Neuron 37:989-999. Medline

Poolos NP, Migliore M, Johnston D (2002) Pharmacological upregulation of $\mathrm{h}$-channels reduces the excitability of pyramidal neuron dendrites. Nat Neurosci 5:767-774. CrossRef Medline

Prinz AA, Billimoria CP, Marder E (2003) Alternative to hand-tuning conductance-based models: construction and analysis of databases of model neurons. J Neurophysiol 90:3998-4015. CrossRef Medline

Prinz AA, Bucher D, Marder E (2004) Similar network activity from disparate circuit parameters. Nat Neurosci 7:1345-1352. CrossRef Medline

R Core Team (2014) R: a language and environment for statistical computing.

Rabinowitch I, Segev I (2006) The endurance and selectivity of spatial patterns of long-term potentiation/depression in dendrites under homeostatic synaptic plasticity. J Neurosci 26:13474-13484. CrossRef Medline

Rabinowitch I, Segev I (2008) Two opposing plasticity mechanisms pulling a single synapse. Trends Neurosci 31:377-383. CrossRef Medline

Rathour RK, Narayanan R (2012a) Inactivating ion channels augment robustness of subthreshold intrinsic response dynamics to parametric variability in hippocampal model neurons. J Physiol 590: 5629-5652. CrossRef Medline

Rathour RK, Narayanan R (2012b) Influence fields: a quantitative framework for representation and analysis of active dendrites. $J$ Neurophysiol 107:2313-2334. CrossRef Medline

Rathour RK, Narayanan R (2014) Homeostasis of functional maps in active dendrites emerges in the absence of individual channelostasis. Proc Nat Acad Sci U S A 111:E1787-1796. CrossRef Medline

Reid MS, Brown EA, DeWeerth SP (2007) A parameter-space search algorithm tested on a Hodgkin-Huxley model. Biol Cybernet 96: 625-634. CrossRef Medline

Reimann MW, Anastassiou CA, Perin R, Hill SL, Markram H, Koch C (2013) A biophysically detailed model of neocortical local field potentials predicts the critical role of active membrane currents. Neuron 79:375-390. CrossRef Medline 
Remy S, Beck H, Yaari Y (2010) Plasticity of voltage-gated ion channels in pyramidal cell dendrites. Curr Opin Neurobiol. CrossRef

Rosenkranz JA, Frick A, Johnston D (2009) Kinase-dependent modification of dendritic excitability after long-term potentiation. J Physiol 587:115-125. CrossRef Medline

Ross WN (2012) Understanding calcium waves and sparks in central neurons. Nat Rev Neurosci 13:157-168. CrossRef Medline

Schomburg EW, Anastassiou CA, Buzsáki G, Koch C (2012) The spiking component of oscillatory extracellular potentials in the rat hippocampus. J Neurosci 32:11798-11811. CrossRef Medline

Schomburg EW, Fernandez-Ruiz A, Mizuseki K, Berényi A, Anastassiou CA, Koch C, Buzsáki G (2014) Theta phase segregation of input-specific gamma patterns in entorhinal-hippocampal networks. Neuron 84:470-485. CrossRef Medline

Schulz DJ, Goaillard JM, Marder E (2006) Variable channel expression in identified single and electrically coupled neurons in different animals. Nat Neurosci 9:356-362. CrossRef Medline

Schulz DJ, Goaillard JM, Marder EE (2007) Quantitative expression profiling of identified neurons reveals cell-specific constraints on highly variable levels of gene expression. Proc Natl Acad Sci U S A 104:13187-13191. CrossRef Medline

Shah MM, Hammond RS, Hoffman DA (2010) Dendritic ion channel trafficking and plasticity. Trends Neurosci 33:307-316. CrossRef Medline

Shah MM, Migliore M, Brown DA (2011) Differential effects of Kv7 (M-) channels on synaptic integration in distinct subcellular compartments of rat hippocampal pyramidal neurons. J Physiol 589: 6029-6038. CrossRef Medline

Sheffield ME, Dombeck DA (2015) Calcium transient prevalence across the dendritic arbour predicts place field properties. Nature 517:200-204. CrossRef Medline

Siegel JM (2001) The REM sleep-memory consolidation hypothesis. Science 294:1058-1063. CrossRef Medline

Siegel M, Marder E, Abbott LF (1994) Activity-dependent current distributions in model neurons. Proc Nat Acad Sci U S A 91: 11308-11312. Medline

Simoncelli EP (2003) Vision and the statistics of the visual environment. Curr Opin Neurobiol 13:144-149. Medline

Simoncelli EP, Olshausen BA (2001) Natural image statistics and neural representation. Annu Rev Neurosci 24:1193-1216. CrossRef Medline

Sinha M, Narayanan R (2015) HCN channels enhance spike phase coherence and regulate the phase of spikes and LFPs in the theta-frequency range. Proc Nat Acad Sci U S A 112:E2207-2216. CrossRef Medline

Sjöström PJ, Rancz EA, Roth A, Häusser M (2008) Dendritic excitability and synaptic plasticity. Physiol Rev 88:769-840. CrossRef Medline

Sneyd J, Keizer J, Sanderson MJ (1995) Mechanisms of calcium oscillations and waves: a quantitative analysis. FASEB J 9:14631472. Medline

Spruston N (2008) Pyramidal neurons: dendritic structure and synaptic integration. Nat Rev Neurosci 9:206-221. CrossRef Medline

Stemmler M, Koch C (1999) How voltage-dependent conductances can adapt to maximize the information encoded by neuronal firing rate. Nat Neurosci 2:521-527. CrossRef Medline

Steriade M (2004) Acetylcholine systems and rhythmic activities during the waking-sleep cycle. Prog Brain Res 145:179-196. CrossRef Medline

Stickgold R (2005) Sleep-dependent memory consolidation. Nature 437:1272-1278. CrossRef Medline

Stickgold R, Fosse R, Walker MP (2002) Linking brain and behavior in sleep-dependent learning and memory consolidation. Proc Nat Acad Sci U S A 99:16519-16521. CrossRef Medline

Takahashi H, Magee JC (2009) Pathway interactions and synaptic plasticity in the dendritic tuft regions of CA1 pyramidal neurons. Neuron 62:102-111. CrossRef Medline
Taylor AL, Goaillard JM, Marder E (2009) How multiple conductances determine electrophysiological properties in a multicompartment model. J Neurosci 29:5573-5586. CrossRef Medline

Thattai M, van Oudenaarden A (2001) Intrinsic noise in gene regulatory networks. Proc Nat Acad Sci U S A 98:8614-8619. CrossRef Medline

Tobin AE, Van Hooser SD, Calabrese RL (2006) Creation and reduction of a morphologically detailed model of a leech heart interneuron. J Neurophysiol 96:2107-2120. CrossRef Medline

Tobin AE, Cruz-Bermúdez ND, Marder E, Schulz DJ (2009) Correlations in ion channel mRNA in rhythmically active neurons. PloS One 4:e6742. CrossRef Medline

Toledo-Rodriguez M, Blumenfeld B, Wu C, Luo J, Attali B, Goodman $\mathrm{P}$, Markram H (2004) Correlation maps allow neuronal electrical properties to be predicted from single-cell gene expression profiles in rat neocortex. Cereb Cortex 14:1310-1327. CrossRef Medline

Tononi G, Cirelli C (2006) Sleep function and synaptic homeostasis. Sleep Med Rev 10:49-62. CrossRef Medline

Triesch J (2007) Synergies between intrinsic and synaptic plasticity mechanisms. Neural Comput 19:885-909. CrossRef Medline

Tsay D, Dudman JT, Siegelbaum SA (2007) HCN1 channels constrain synaptically evoked $\mathrm{Ca} 2+$ spikes in distal dendrites of CA1 pyramidal neurons. Neuron 56:1076-1089. CrossRef Medline

Turrigiano G (2007) Homeostatic signaling: the positive side of negative feedback. Curr Opin Neurobiol 17:318-324. CrossRef Medline

Turrigiano G (2011) Too many cooks? Intrinsic and synaptic homeostatic mechanisms in cortical circuit refinement. Annu Rev Neurosci 34:89-103. CrossRef Medline

Turrigiano GG (1999) Homeostatic plasticity in neuronal networks: the more things change, the more they stay the same. Trends Neurosci 22:221-227. Medline

Turrigiano GG, Nelson SB (2000) Hebb and homeostasis in neuronal plasticity. Curr Opin Neurobiol 10:358-364. Medline

Turrigiano GG, Nelson SB (2004) Homeostatic plasticity in the developing nervous system. Nat Rev Neurosci 5:97-107. CrossRef Medline

Vacher H, Mohapatra DP, Trimmer JS (2008) Localization and targeting of voltage-dependent ion channels in mammalian central neurons. Physiol Rev 88:1407-1447. CrossRef Medline

Vaidya SP, Johnston D (2013) Temporal synchrony and gamma-totheta power conversion in the dendrites of CA1 pyramidal neurons. Nat Neurosci 16:1812-1820.

Vertes RP (1984) Brainstem control of the events of REM sleep. Prog Neurobiol 22:241-288. Medline

Walker MP, Stickgold R (2004) Sleep-dependent learning and memory consolidation. Neuron 44:121-133. CrossRef Medline

Weaver CM, Wearne SL (2008) Neuronal firing sensitivity to morphologic and active membrane parameters. PLoS Comput Biol 4:e11. CrossRef Medline

Wilson MA, McNaughton BL (1994) Reactivation of hippocampal ensemble memories during sleep. Science 265:676-679. Medline Ylinen A, Bragin A, Nádasdy Z, Jandó G, Szabó I, Sik A, Buzsáki G (1995) Sharp wave-associated high-frequency oscillation $(200 \mathrm{~Hz})$ in the intact hippocampus: network and intracellular mechanisms. J Neurosci 15:30-46. Medline

Yu RC, Pesce CG, Colman-Lerner A, Lok L, Pincus D, Serra E, Holl M, Benjamin K, Gordon A, Brent R (2008) Negative feedback that improves information transmission in yeast signalling. Nature 456 : 755-761. CrossRef Medline

Zador A, Koch C (1994) Linearized models of calcium dynamics: formal equivalence to the cable equation. J Neurosci 14:47054715. Medline

Zhang W, Linden DJ (2003) The other side of the engram: experience-driven changes in neuronal intrinsic excitability. Nat Rev Neurosci 4:885-900. CrossRef Medline 